Andrews University

Digital Commons @ Andrews University

\title{
Mindset, Academic Motivation, And Academic Self-Efficacy As \\ Correlates Of Academic Achievement Among Undergraduate Students in Communication Sciences and Disorders Programs
}

Heather Loraine Ferguson

Andrews University, hferguson@andrews.edu

Follow this and additional works at: https://digitalcommons.andrews.edu/dissertations

Part of the Communication Commons, and the Higher Education Commons

\section{Recommended Citation}

Ferguson, Heather Loraine, "Mindset, Academic Motivation, And Academic Self-Efficacy As Correlates Of Academic Achievement Among Undergraduate Students in Communication Sciences and Disorders Programs" (2017). Dissertations. 1648.

https://digitalcommons.andrews.edu/dissertations/1648

https://dx.doi.org/10.32597/dissertations/1648

This Dissertation is brought to you for free and open access by the Graduate Research at Digital Commons @ Andrews University. It has been accepted for inclusion in Dissertations by an authorized administrator of Digital Commons@ Andrews University. For more information, please contact repository@andrews.edu. 


\begin{abstract}
MINDSET, ACADEMIC MOTIVATION, AND ACADEMIC SELF-EFFICACY AS CORRELATES OF ACADEMIC ACHIEVEMENT AMONG UNDERGRADUATE STUDENTS IN COMMUNICATION SCIENCES AND DISORDERS PROGRAMS
\end{abstract}

by

Heather Loraine Ferguson

Chair: Elvin Gabriel 


\title{
ABSTRACT OF GRADUATE STUDENT RESEARCH
}

Dissertation

\author{
Andrews University \\ School of Education
}

\section{Title: MINDSET, ACADEMIC MOTIVATION, AND ACADEMIC SELF-EFFICACY AS CORRELATES OF ACADEMIC ACHIEVEMENT AMONG UNDERGRADUATE STUDENTS IN COMMUNICATION SCIENCES AND DISORDERS PROGRAMS}

Name of researcher: Heather Loraine Ferguson

Name and degree of faculty chair: Elvin Gabriel, Ed.D.

Date completed: September 2017

\section{Problem}

Higher education serves many stakeholders including students, parents, faculty, staff, university administrators, and other contributors. Those stakeholders are all linked with one purpose: the success of the student. That success or failure is most commonly measured by achievement through grade point average (GPA). The academic demands within the college/university setting is high. Limited academic achievement can result in academic failure, being placed on academic probation, even losing scholarships and grants. Students enter college, progress through college, and often graduate without having a real understanding for what it truly takes to be academically successful and what 
factors may contribute to that success. The study examined the extent to which types of mindset, academic motivation, and academic self-efficacy correlated with academic achievement among undergraduate communication sciences and disorders students.

\section{Method}

Undergraduate communication sciences and disorders students in the Great Lakes States of Michigan, Indiana, Ohio, and Illinois completed a 75-item survey to determine the correlation between academic achievement and mindset, academic motivation, and academic self-efficacy. Descriptive analysis, Spearman Rank correlation, and categorical regression (CATREG) were used to analyze the data.

\section{Results}

Results of this current study indicate that undergraduate communication sciences and disorders students report average to higher than average GPAs. Undergraduate communication sciences and disorders students have very high extrinsic motivation $(M=$ 5.90), high intrinsic motivation $(M=5.22)$, and very low amotivation $(M=1.62)$.

Fifty-four percent of undergraduate communication sciences and disorders students have high self-efficacy and higher growth mindset than fixed mindset. The results of this study indicate that amotivation is negatively correlated to academic achievement. Therefore, the higher the academic achievement, the lower the amotivation. Academic self-efficacy is also correlated to academic achievement. Hence, the higher the academic self-efficacy, the higher the academic achievement. 


\section{Conclusions}

Undergraduate communication sciences and disorders students, who are "average to higher than average" in their academic achievement are more extrinsically motivated. They present with almost no amotivation, and have generally high self-efficacy. The undergraduate communication disorders student has more of a growth mindset than a fixed mindset. This population is resilient, motivated more by externally contributing factors, and demonstrates learning-based development and changeability. They have positive feelings about their academic skills which are found to be directly related to their average to high-average academic achievement. 
Andrews University

School of Education

MINDSET, ACADEMIC MOTIVATION, AND ACADEMIC SELF-EFFICACY AS CORRELATES OF ACADEMIC ACHIEVEMENT AMONG UNDERGRADUATE STUDENTS IN COMMUNICATION SCIENCES AND DISORDERS PROGRAMS

\author{
A Dissertation \\ Presented in Partial Fulfillment \\ of the Requirements for the Degree \\ Doctor of Philosophy
}

by

Heather Loraine Ferguson

September 2017 
(C) Copyright by Heather Loraine Ferguson 2017

All Rights Reserved 


\title{
MINDSET, ACADEMIC MOTIVATION, AND ACADEMIC SELF-EFFICACY AS CORRELATES OF ACADEMIC ACHIEVEMENT AMONG UNDERGRADUATE STUDENTS IN COMMUNICATION SCIENCES AND DISORDERS PROGRAMS
}

\author{
A dissertation \\ presented in partial fulfillment \\ of the requirements for the degree \\ Doctor of Philosophy
}

by

Heather Loraine Ferguson

APPROVAL BY THE COMMITTEE:

Chair: Elvin Gabriel

Dean, School of Education

Robson Marinho

Member: Jimmy Kijai

Member: Gustavo Gregorutti

External: Rhonda Tomenko

Date approved 


\section{TABLE OF CONTENTS}

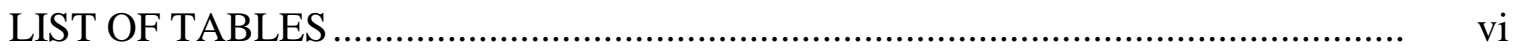

LIST OF ABBREVIATIONS ...................................................................... viii

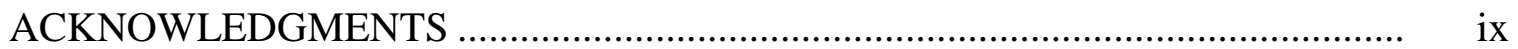

\section{Chapter}

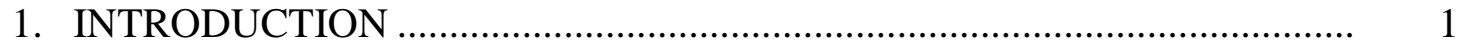

Background ...............................................................................

Rationale for the Study ………………………………………...... 5

Statement of the Problem..................................................................

Purpose of the Study ........................................................................

Conceptual Framework ...................................................................... 9

Linking Mindset and Academic Achievement ................................... 14

Linking Academic Motivation and Academic Achievement............... 14

Linking Self-Efficacy and Academic Achievement ........................... 14

Linking Academic Achievement, Self-Efficacy, Mindset, and Academic Motivation .......................................................... 15

Research Questions .................................................................... 16

Significance of the Study ............................................................... 16

Definition of Terms.................................................................... 18

Limitations of the Study ................................................................ 20

Delimitations of the Study ............................................................. 21

Organization of the Study ……………............................................ 21

2. LITERATURE REVIEW ............................................................... 22

Purpose of Literature Review ........................................................... 22

A Historical Overview of Academic Achievement ............................ 23

A Historical Overview of Mindset.................................................... 25

A Historical Overview of Academic Motivation................................. 26

A Historical Overview of Academic Self-Efficacy …………............. 27

The Relationship Between Mindset and Academic Achievement....... 29

The Relationship Between Academic Motivation and Academic

Achievement ...................................................................... 34

The Relationship Between Academic Self-Efficacy and

Academic Achievement ............................................................... 41 
Brief Summary of Literature..................................................... 44

3. METHODOLOGY …..................................................................... 45

Introduction ........................................................................... 45

Research Questions ........................................................... 45

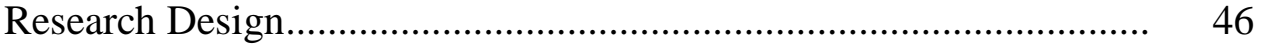

Population and Sample ................................................................ 47

Instrumentation .................................................................. 48

Procedure …................................................................. 51

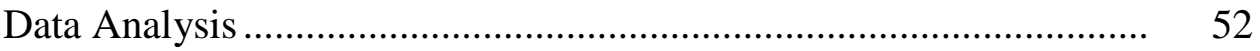

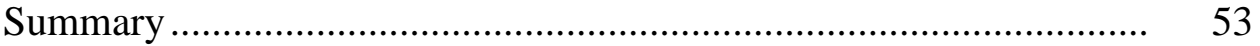

4. ANALYSIS OF DATA....................................................................... 54

Description of the Sample........................................................ 54

Demographic Information......................................................... 55

Research Questions ............................................................... 57

Research Question 1 ........................................................ 57

Mindset ..................................................................... 57

Academic Motivation..................................................... 60

Academic Self-Efficacy ...................................................... 63

Research Question 2 ....................................................... 68

Summary of Major Findings .................................................. $\quad 74$

5. SUMMARY, DISCUSSION, AND IMPLICATIONS .............................. 76

Introduction ........................................................................ 76

Purpose of the Study .............................................................. 76

Summary of Literature ............................................................ 76

Summary of Methodology .......................................................... 81

Summary of Major Findings ................................................... 81

Demographic Information................................................... 82

Research Question 1 Discussion .............................................. 83

Research Question 2 Discussion ................................................... 86

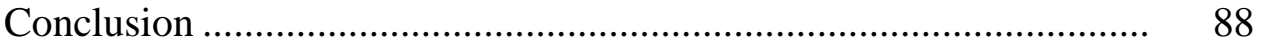

Implications for Practice ..................................................... 90

Implications for Future Research ........................................... 92

Appendix

A. IRB APPROVAL DOCUMENTS ....................................................... 94

B. SURVEY INVITATION ................................................................. 97

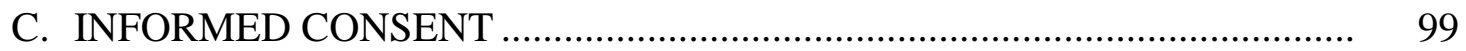




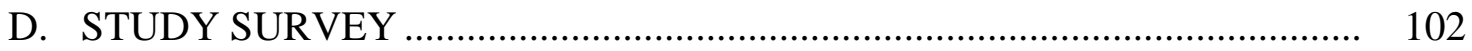

E. SCALE USE PERMISSIONS _.............................................................. 107

REFERENCE LIST ........................................................................... 111

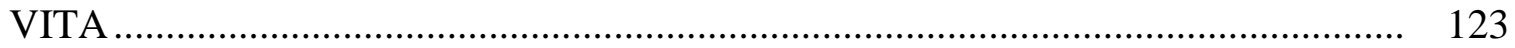




\section{LIST OF TABLES}

1. Survey Item Distribution.....

2. Reliability for Mindset, Academic Motivation and Academic Self-Efficacy.......

3. Undergraduate Communication Sciences and Disorders Students'

Demographic

4. Descriptive Statistics of Independent Variables

5. Levels of Types of Mindset

6. Descending Descriptive Statistics of Growth Mindset

7. Descending Descriptive Statistics of Fixed Mindset

8. Levels of Types of Academic Motivation

9. Descending Descriptive Statistics of Intrinsic Motivation

10. Descending Descriptive Statistics of Extrinsic Motivation

11. Descending Descriptive Statistics of Amotivation

12. Levels of Academic Self-Efficacy

13. Descending Descriptive Statistics of Academic Self-Efficacy

14. Spearman Rank Correlation of GPA, Mindset, Academic Motivation, and Academic Self-Efficacy

15. Correlations, Coefficients, $p$ Values, and Importance of Mindset (Fixed Mindset, Growth Mindset) to GPA (CATREG)

16. Correlations, Coefficients, $p$ Values, and Importance of Mindset (Fixed Mindset, Growth Mindset) and Motivation (Intrinsic, Extrinsic and Amotivation) to GPA (CATREG) 
17. Correlations, Coefficients, $p$ Values, and Importance of Mindset (Fixed Mindset, Growth Mindset), Motivation (Intrinsic, Extrinsic and Amotivation), and Self-Efficacy to GPA (CATREG). 


\section{LIST OF ABBREVIATIONS}

$\begin{array}{ll}\text { AMS } & \text { Academic Motivation Scale } \\ \text { ASHA } & \text { American Speech-Language and Hearing Association } \\ \text { CASES } & \text { College Academic Self-Efficacy Scale } \\ \text { CATREG } & \text { Categorical Regression } \\ \text { EPT } & \text { Education Productivity Theory } \\ \text { GPA } & \text { Grade Point Average } \\ \text { IRB } & \text { Institutional Review Board } \\ \text { SAT } & \text { Scholastic Aptitude Test } \\ \text { SD } & \text { Standard Deviation } \\ \text { SDT } & \text { Self-Determination Theory } \\ \text { SPSS } & \text { Statistical Package for Social Science }\end{array}$




\section{ACKNOWLEDGMENTS}

I would like to thank my family for their constant support through this journey. I especially want to thank my husband Mario for all of the meals made, words of encouragement, and prayers. Micah and Malaika, you are the best! Thank you so much for never letting me quit and for holding me to the highest "teenage" standards ever. To my parents (Mary and Eric Dunkley), my sister and brother-in-law Natalie and Jared Francis, my mother-in-law Monica Ferguson, and the rest of my family. Your prayers, support, and constant reassurance have been invaluable.

To the faculty, staff, and students of the Department of Speech-Language

Pathology and Audiology, thank you so much for your prayers, understanding, and encouragement through this journey. You have helped to keep me sane and allow the time for me to enjoy this process. Dr. Emmanuel Rudatsikira, thank you for your mentorship and advice. To Ivan Davis and Laura Carroll, your support has been instrumental.

Dr. Elvin Gabriel, you have been an amazing support. Your knowledge and experience have been instrumental to the completion of this project. Dr. Jimmy Kijai and Dr. Gustavo Gregorutti, thank you for agreeing to serve on my committee and offering your expertise. I could not have done it without the three of you! 


\section{CHAPTER 1}

\section{INTRODUCTION}

\section{Background}

Student success from the perspective of higher education administration is an institution's primary goal. That desired success drives the organization from the level of governance to staff/student interaction. The importance of educational achievement in the United States was summarized in 2009 by President Barack Obama who stated that "by 2020, America will have the best-educated, most competitive workforce in the world

with the highest proportion of college graduates of any country" (Kanter, Ochoa, Nassif, \& Chong, 2011). This goal places this productive reality at the feet of instructors, administrators, employers, parents, and teachers. While some may say that the overall student experience and the opportunity to educate someone who will become a valuable member of society is paramount, the main methodology and the gold standard for measuring student achievement in college is grade point average (GPA) (Mansharamani, 2016). It is understood that many entering college/university must have strong test scores on assessments such as the American College Testing, the Scholastic Aptitude Test (SAT), and high school GPA. However, once matriculated, students' college GPA is the tell-tale sign of whether success or failure occurs (Strang, 2015). The fact that many in higher education have a limited understanding of why and how they achieve academic success in certain areas more than others leaves stakeholders restricted in their quest for 
consistent mentorship of strong societal leaders and global contributors.

Higher education in the 21 st century has experienced a shift. Gone are the days when higher education could only be accessed by an elite group. It is agreed that with access to educational loan, grant programs, and online education, higher education has become more accessible to the "average" American (Goldrick-Rab \& Cook, 2011). With this greater access comes greater responsibility, greater diversity, and a greater need for understanding what factors drive this population to succeed. One way of understanding student academic achievement is through clearer insight into the role of factors such as mindset, academic motivation, and academic self-efficacy (Bandura, 1977; Deci \& Ryan, 1985; Dweck, 2006; Ryan \& Deci, 2017). However, the receipt of high grades does not always ensure knowledge, learning, and the internalization of information. Deci and Ryan (2002) posited that "high scores on standardized tests do not ensure excellent education" (p. 62). High academic achievement is usually based on GPA, which ranges from 0.0 (lowest) to 4.0 (highest) (Strang, 2015). Some would speculate that the same could be said about college academic achievement. The current average GPA for undergraduate students attending a four-year institution is 3.1 (Lindsay, 2015). There are speculations that college GPAs are inflated and do not necessarily reflect true ability (Strang, 2015). However, even with the controversial topic of college grade inflation, GPA is the gold standard for assessing academic success or failure at the college level (Mansharamani, 2016).

Through the application of various factors, many have studied academic achievement as a means of understanding its impact and relevance to the student (Deci \& Ryan, 1985; Elliot \& Harackiewicz, 1994; Maurer, Allen, Gatch, Shankar, \& Sturges, 
2012). Academic achievement is defined as

a student's success in meeting short- or long-term goals in education. In the big picture, academic achievement means completing high school or earning a college degree. In a given semester, high academic achievement may mean a student is on the honor roll. (Academic achievement, 2017)

This definition gives clear indication that academic achievement is the end result of the college academic experience.

The field of Communication Sciences and Disorders has been in existence for many years and is visible in history. King George VI who was King of England during World War II was a known stutterer and received help from a "speech therapist." With the support of his wife and his speech therapist, he was able to give one of the most famous speeches in history, announcing to the citizens of Britain that they were at war (Hooper, 2010). The movie My Fair Lady depicts a "phonetics professor" who worked with a young indigent woman on improving her speech, etiquette, and diction (Cukor, 1964). What Professor Henry Higgins performed in its crudest sense was a form of speech therapy. Now as a formal profession throughout the United States, over forty thousand students claim communication sciences and disorders as their college major (American Speech-Language and Hearing Association [ASHA], 2017). While academic achievement, academic motivation, mindset, and self-efficacy have been studied and reported in populations from science, technology, engineering and mathematics, elementary school, and college students overall (Dweck \& Leggett, 1988; Murphy \& Thomas, 2008; Zimmerman, Bandura, \& Martinez-Pons, 1992), very little is known about this population of college students. A better understanding of the correlation of academic achievement to academic motivation, mindset, and self-efficacy could be critical to learning more about this student group and how they learn, apply knowledge, 
motivate themselves, persist, and succeed.

Undergraduate communication sciences and disorders students major in the foundational studies necessary for advancement to a graduate degree program in speechlanguage pathology or audiology. As noted, these programs are highly competitive with GPA being one of the main components of graduate school acceptance. Most graduate programs require a 3.0 GPA, with acceptance GPAs ranging between 3.4 and 4.0 (Edfind, 2014). According to the Academic Affairs Board (2015) of ASHA, in order to be prepared for graduate studies in communication sciences and disorders, students must possess and demonstrate general knowledge, skills, aptitude, and experiences in social, biological, physical science foundations, and behavioral domains. Within the specific area of communication sciences and disorders, students must have specific knowledge, skills, aptitude, and experiences in normal and abnormal speech, language, hearing, and swallowing domains. As is common with many academic disciplines, communication sciences and disorders program stakeholders are constantly seeking methods of increasing student readiness, performance, and persistence. Those efforts are derived from academic perspectives, with attempts to increase academic rigor, restructure and redefine pedagogical approaches, and develop standards to attract and retain "the best students" (Scudder, Aarts, Golper, \& Groher, 2009). However, few stakeholders have discussed examining and understanding the academic achievement or underachievement of the students, and how that knowledge could affect growth, development, and the success of the undergraduate communication sciences and disorders student. Such data is limited within the research literature and has been focused on graduate student recruitment and retention (Saenz, 2000). 
With the need to understand this population, the study of mindset, academic motivation, and academic self-efficacy are important applicable factors in academic achievement. Studies have found that academic motivation and autonomous choosing of goals both positively correlate and are a construct of academic achievement (Conti, 2000). Motlagh, Amrai, Yazdani, Abderahim, and Souri (2011) noted that "self-efficacy is a considerable factor in academic achievement" (p. 765). Further, research has consistently revealed that one's mindset can affect academic achievement by affecting performance, resiliency, and persistence. Blackwell, Trzesniewski, and Dweck (2007) found that students with a growth mindset, a core belief that abilities are malleable, demonstrated increased motivation, grades, and achievement. Students possessing this form of malleability, related to intelligence, who demonstrate greater levels of academic achievement also demonstrate greater levels of intrinsic motivation (Briceno, 2012; Dweck, 2006, 2014; Dweck \& Leggett, 1988).

This study explored the relationships between mindset, academic motivation and academic self-efficacy, and academic achievement of students pursuing an undergraduate degree in the field of communication sciences and disorders at selected Great Lakes States universities. Such critical relationships may prove valuable information for students, higher education administrators, faculty, parents, and the medical and educational industries at large.

\section{Rationale for the Study}

Student achievement is critical to the success of higher education institutions. Walberg (1984) defined education as a productivity industry, much like the steel industry or the automotive industry. The industry of education was valued as a 815-billion-dollar 
industry in 1984 with a declining product asset load over the last several decades. There are several factors that impact education, and ultimately achievement, including student ability, age, motivation, time spent engaged in learning, quality of instruction, home environment, school environment, peer group choices, and time spent out-of-school (Walberg, 1984).

Ali, Haider, Munir, Khan, and Ahmed (2013) stated that "students' academic gain and learning performance is affected by numerous factor including gender, age, teaching faculty, students schooling, father/guardian social economic status, residential area of students, medium of instructions in schools, tuition trend, daily study" (p. 283). Factors such as mindset, academic motivation, and academic self-efficacy contribute to levels of academic achievement in students from elementary school to college (Bandura, 1977; Deci \& Ryan, 1985; Dweck, 2006; Dweck \& Leggett, 1988; Schunk, 1991).

While academic achievement, self-efficacy, academic motivation, and mindset have been studied extensively (Bandura, 1977; Deci \& Ryan, 1985; Dweck, 2006; Walberg, 1984), few studies have been conducted on the mindset, academic motivation and academic achievement of students pursuing degrees in communication sciences and disorders. Stakeholders in higher education and the healthcare industry are expecting them to fill important positions in this field after graduation. These students are those who will persist to complete advanced terminal degrees in either speech-language pathology or audiology, both areas of national shortage (Bureau of Labor and Statistics, 2015). The demands are high and graduate program entrances are competitive. According to ASHA, approximately 40,528 students were enrolled in undergraduate communication science and disorders programs from 2010 to 2015 in the United States. 
During the same five-year period, over 10,789 students graduated with an undergraduate degree in communication sciences and disorders. Graduate programs in both speechlanguage pathology and audiology reported a median admission capacity of 38 (approximately 9,000 slots) with 99\% enrollment in these programs (Communication Sciences and Disorders Education Trend Data Undergraduate Program, n.d.).

Consideration for entrance into graduate programs in speech-language pathology and audiology is also given to those from different undergraduate fields of study, as well as to former students who already hold an undergraduate communication sciences and disorders degree. These numbers clearly indicate a much larger applicant pool than available graduate school slots, leading to a highly competitive and much-anticipated process. Undergraduate students are counseled to apply to many schools and based on their GPA, they may have to apply to upwards of 10 programs. The academic rigor, competitive vetting process of graduate program acceptance and persistence makes gaining a better understanding of the academic achievement factors of this group critical (Communication Sciences and Disorders Education Trend Data Undergraduate Program, n.d.).

\section{Statement of the Problem}

Higher education serves many stakeholders including students, parents, faculty, staff, and university administrators. Those stakeholders are linked with one purpose: the success of the student. That success or failure is most commonly measured by academic achievement through GPA. The academic demands within the college/university setting are high. There is little room for failure. Limited academic achievement could result in academic failure, which places students at risk of being placed on academic probation, 
losing financial aid eligibility, experiencing obstacles in gaining acceptance to graduate programs, and not persisting to completion due to dismissal from academic programs and/or institutions (Why a low gpa is a problem, why it might be low, and how to raise it, n.d.).

Numerous researchers have studied academic achievement and underachievement (Balduf, 2009; Neumeister \& Hebert, 2003; Voegeli, 2008). Reasons for low achievement may be the absence of useful study skills, limited parental educational level, socioeconomics, fear of failure, fear of success, parental and teacher expectations, social aspects and innate characteristics of students' attitudes and social-cognitive influences such as academic self-efficacy, academic motivation, and mindset (Deci \& Ryan, 1985; Dweck \& Leggett, 1988; Erdem, Senturk, \& Arslan, 2007; Gallagher, n.d.; Schunk, 1991).

Despite all that is known about academic achievement, there are cognitively proficient students who continue to underachieve academically. There are also those who achieve academic proficiency without a real understanding of how, why, and the level at which internal factors may impact their achievement. Research has identified many internal and external variables that are linked to academic achievement at the college level (Deci \& Ryan, 1985; Dweck \& Leggett, 1988; Erdem, Senturk, \& Arslan, 2007; Gallagher, n.d.; Schunk, 1991). Balduf (2009) denoted that researchers must develop a better understanding not only for the behavior of underachievement (hence achievement), but also for the insightful examination of the attitudes that propel the behaviors. Contemporary research urges the continued exploration of academic achievement from the student's perspective as an instrumental means of understanding academic 
achievement (Neumeister \& Hebert 2003). Researchers have denoted that mindset, academic motivation, and academic self-efficacy impact academic achievement to varying extents with conflicting information as to what degree, making such knowledge critical to the understanding of academic achievement of the undergraduate college student (Bandura, 1977; Deci \& Ryan, 1985; Dweck \& Leggett, 1988; Leal, Miranda, \& Souza, 2012; Planchard, Daniel, Maroo, Mishra, \& McLean, 2015; Robbins et al., 2004; Schunk, 1991).

\section{Purpose of the Study}

The purpose of the study was to determine the extent to which types of mindset, types of academic motivation, and levels of academic self-efficacy were correlated with the academic achievement of students pursuing an undergraduate degree in the field of communication sciences and disorders in selected Great Lakes States universities.

\section{Conceptual Framework}

The conceptual framework focused on four theories that undergirded the dependent and independent variables of this study. The first was the Education Productivity Theory (EPT), developed by Herbert Walberg in 1984. Walberg based the EPT on the industrial model of economics to explain education as a viable product. The second was the Implicit Theories of Intelligence (Dweck, 2006; Dweck \& Leggett, 1988), which describes and analyzes the mindset construct. Mindset has been applied to achievement, motivation, and resilience at all levels of education (Blackwell et al., 2007;

Diseth, Meland \& Breidablik, 2014; Dweck \& Leggett, 1988). The third was the SelfDetermination Theory (SDT) (Deci \& Ryan, 1985), which focused on the effects of 
various types of academic motivation. The fourth was academic self-efficacy, which was based on the social cognitive theory coined by Albert Bandura in 1977.

This current study was based on the primary conceptual framework of the EPT (Walberg, 1984; 2003). The EPT is explained through the adaptation of an industrial economic model. Noting that if academic achievement were looked at as a product based on factors such as federal educational cost and academic program completion rates, the product of education would be found to be stagnant and, in some instances, declining (Walberg, 2003, p. 2).

Walberg (1984) posited that in order to increase student learning, there must be an optimal balance of affective, behavioral, and cognitive learning. The nine factors of EPT are classified within three components: student aptitude, instructional methodology, and environmental factors. Student aptitude is concerned with students' prior achievement, chronological age development, and motivation to persist to task completion (Walberg, 1984). For the purposes of this study, motivation as understood through the learning productive theory is applied.

McGrew (2011) investigated the reasons given by students for completing a task. He stated that "student characteristics related to this question include, but are not limited to, achievement interests and values, intrinsic motivation, academic goal orientation, and social goals and their relations to motivation" (para. 2). As noted motivation, and specifically academic motivation, are strongly linked to mindset and academic selfefficacy, and academic achievement.

In her book titled Mindset: The New Psychology of Success, Dweck (2006) emphasized that there are "fixed" and "growth" mindsets that can predict success, 
resilience, and even one's ability to learn new information and persevere academically and in life. Those with a fixed entity mindset are less malleable and less flexibile hence, less likely to succeed if given difficult or challenging learning tasks and environments. They are more likely to exhibit the characteristics of "learned helplessness." In an academic setting, these students are more likely to give up when challenges arise. They are apt to become disheartened and dejected when the praise and accolades they work for are not bestowed. If they fail at a task, the immediate assumption is that they are not smart. Those with a growth incremental mindset are more malleable and note most experiences as learning experiences. Those with a growth mindset do not only work for a grade, but also for the benefit of learning information and becoming more knowledgeable (Blackwell et al., 2007; Briceno, 2012; Dweck, 2006). The underlying premise of mindset is that success is not just based on resiliency, effort, or focus, but also on the growth mindset.

The SDT is constructed from an integration of two sub-theories, namely, the Cognitive Evaluation Theory, and the Organismic Integration Theory (Deci \& Ryan, 1985). The Cognitive Evaluation Theory explains how competence, autonomy, and relatedness together lead to intrinsic motivation, and the Organismic Integration Theory explains how activities can come to be valued through different types of regulations including intrinsic, extrinsic, and amotivation (Jones, 2014). These theories affirm that motivation can be qualitative, rather than quantitative, while manifesting itself quantitatively (GPA). Competence, autonomy, and relatedness must also be in balance in order for a task or experience to be enjoyable, retained, and internalized. These outcomes produce levels of creativity, problem-solving, performance, positive emotion, and 
psychological and physical wellness (Deci, 2012). Intrinsic motivation, the most positive form of motivation is experienced when an individual completes a task or an activity for the enjoyment of doing so. They are satisfied not only following the experience, but also while engaging in it. Extrinsic motivation can affect the level of intrinsic motivation (Deci \& Ryan, 1985).

Deci and Ryan (1985) posited that intrinsic motivation occurs when an individual engages in a behavior or participates in activities simply for the pleasure that is derived from the experience. It comes from a desire for self-determination and competence (Vallerand et al., 1992). Much research has been dedicated to the application of the selfdetermination theory in the field of education, resulting in the term "academic motivation." Vallerand et al. (1992) noted, “This theoretical approach has generated considerable amount of research and appears rather pertinent for the field of education" (p. 1004). Specific intrinsic motivation types such as motivation to know, to accomplish, and to experience stimulation can satisfy an educational need for exploration, learning goals, curiosity, and intrinsic motivation to learn (Clark \& Schroth, 2010; Deci \& Ryan, 1985; Gottfried, 1985; Harter, 1981). Further, there are desires to feel a sense of accomplishment. Specific to its application to academic factors, Vallerand et al. (1992) noted that

students who go to class in order to experience the excitement of stimulating class discussion, or who read a book for the intense feeling of cognitive pleasure derived from passionate and exciting passages represent examples of individuals who are intrinsically motivated to experience stimulation in education (p. 1006).

Often mistaken for self-esteem, which is also known as self-respect, self-efficacy is defined as "a person's belief in his or her ability to succeed in a specific situation" (Strive Together, 2017). First coined by Bandura in 1977, self-efficacy, which is a 
construct of the social cognitive theory, contends that an individual's beliefs about him/herself can directly affect the psychological state, behavior, and motivation, in turn impacting performance. The social cognitive theory argues that environmental (social) factors interact with personal (cognitive) factors, hence affecting behavior. This interconnected reciprocal determinism of the social cognitive theory emphasizes several personal factors including goals, efficacy, the process of self-regulation, and attributions (Cherry, 2016). Thus, an individual's specific capability beliefs are derived from previous experiences of success, observations of the success of others, and encouragement that they have the ability to succeed (Bandura, 1994). Figure 1 gives a visual representation of the conceptual framework of this study.

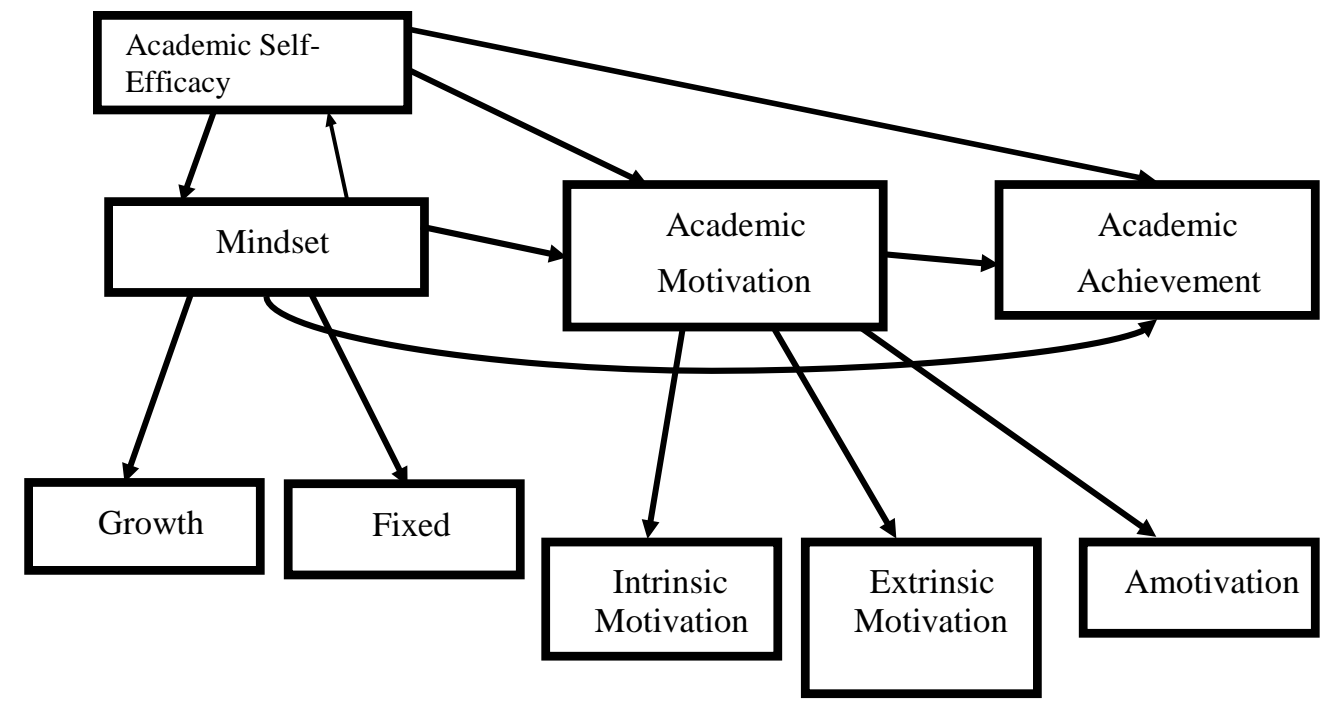

Figure 1. Linking academic achievement, self-efficacy, mindset and academic motivation. Mindset, academic motivation, academic self-efficacy 


\section{Linking Mindset and Academic Achievement}

Growth mindset individuals focus more on mastery goals rather than performance goals (Dweck, 2006). Students who work toward learning rather than working simply for that letter grade tend to grow more as a student and actually tend to perform better.

These were the findings of a study conducted by Claro, Paunesku, and Dweck (2016). The researchers studied 168,000 tenth-grade students in Chile to determine the correlation between mindset and academic achievement. The study confirmed that a growth mindset reliably predicts achievement.

\section{Linking Academic Motivation and Academic Achievement}

Academic motivation is one of the constructs of the EPT, giving way to the direct link of the two factors. Further study has led to the conclusion that academic motivation is strongly linked to academic achievement (Robins et al., 2004). Kusurkar, Cate, Vos, Webster, and Croiset (2012) confirmed this link through their study of university level students. The researchers found that students involved in the study who were intrinsically motivated demonstrated higher levels of academic achievement.

\section{Linking Self-Efficacy and Academic Achievement}

Self-efficacy and academic achievement are also strongly linked. In a study conducted by Robbins et al. (2004), achievement motivation, academic goals, institutional commitment, perceived social support, social involvement, academic selfefficacy, general self-concept, academic-related skills, and contextual influences were measured for correlation to academic achievement (GPA) and college persistence. The study revealed that the strongest link to GPA was that of self-efficacy. The second 
strongest link was achievement motivation (academic motivation). This study confirmed that there is a strong relationship among academic achievement, self-efficacy, and academic motivation.

In a meta-analysis of self-efficacy, Lennon (2010) reiterated that few have attempted to refute Bandura's theory successfully. Experts in the field are somewhat united in agreement of what academic self-efficacy is and what it represents. In young children, self-efficacy tends to be more task specific, however, as children grow and develop, self-efficacy becomes much broader and general (Eccles \& Wigfield, 2002). This is in direct contrast to motivation and eventual academic motivation which begins as a general construct, becoming much more specific and directed as children grow and mature into adulthood (Deci \& Ryan, 1985; Eccles \& Wigfield, 2002). In a detailed description of the characteristics and common behaviors of students with high levels of self-efficacy, Bandura (1997) mentioned that these students tend to look at failure as a lack of effort rather than an academic shortcoming; they commit to task completion, they take constructive critique and apply it, and when faced with failure, they increase their effort to attain success, further linking self-efficacy, academic achievement, and academic motivation.

\section{Linking Academic Achievement, Self-Efficacy, Mindset, and Academic Motivation}

In an exploratory study of the relationships among motivation, self-efficacy, mindsets, attributions, and learning strategies (Lackey, 2013), it was found that selfefficacy is highly correlated to intrinsic motivation as well as growth mindset in 116 college students. When compared to GPA, self-efficacy, academic motivation, and 
mindset showed a significant relationship (p. 87). There was a greater level of significance with the groups that had higher GPAs than those who reported lower GPAs. Further linking the noted factors, Amrai, Motlagh, Zalani, and Parhon (2011) stated,

Above all, concerning the high grade of interest in task, it is safe to say that learners who believe that tasks are worthy and valuable are more concerned with cognitive activities and use more cognitive and monitoring strategies and have basically more academic achievement. Also, once learners inherently value learning, this will have positive effect on self-discipline and self-efficacy. (p. 401)

Individual effort, perseverance, commitment to task, and resilience when there is failure are all strongly linked to levels of academic self-efficacy, type of mindset, and academic motivation (Bandura, 1994; Deci \& Ryan, 1985; Dweck, 2006).

\section{Research Questions}

Research Question 1: What are the types of mindset, types of academic motivation, types of academic self-efficacy, and levels of academic achievement described by students pursuing an undergraduate degree in the field of Communication Sciences and Disorders at selected Great Lakes States universities?

Research Question 2: To what extent are mindset, academic motivation, and academic self-efficacy related to the academic achievement of students pursuing an undergraduate degree in the field of Communication Sciences and Disorders at selected Great Lakes States universities?

\section{Significance of the Study}

The results of this study can be beneficial to higher education personnel as they give guidance and support to communication sciences and disorders students and students from other academic majors. "The success of a student's post-academic career reflects 
upon the university that educated him/her" (Avci, Ring \& Mitchelli, 2016, p. 46). Higher education administrators and faculty are responsible for successfully preparing contributors for the workforce, but their job has not been done. Educators may find that this study leads them to further searches for resources, information, and programs that may help those students who are plagued with and impacted by fixed mindsets, low levels of self-efficacy, and extrinsic motivation or amotivation.

Parents and the students themselves are other stakeholders who may find the resulting data of this study important. Advancing through communication sciences and disorders programs will lead students to a professional degree. This degree prepares students almost immediately for a specifically trained career environment. They are marketable and sought after (Bureau of Labor and Statistics, 2015).

Government agencies and policy makers have had a stake in higher education since the 1944 passing of the GI Bill (Avci, Ring, \& Mitchelli, 2015; Geiger, 2011). Today, those agencies are still concerned with grants and loans such as the PELL Grant and Federal Student Financial Aid (Federal Student Aid, n.d.). These government agencies are concerned with global oversight and most definitely with the flow of qualified men and women into the workforce. If this study is able to extrapolate relationships that are key to academic achievement, fewer students will "drop out," leaving partially obtained degrees, loan repayments for no earned degree, and ultimately, fewer professionals entering the workforce.

There is little research for the undergraduate communication sciences and disorders student population. In 2014, over 40,000 students in the United States identified themselves as undergraduate communication sciences and disorders students 
(Communication Sciences and Disorders Education Trend Data Undergraduate Program,

n.d.). Over 20,000 students were enrolled in graduate programs for which the undergraduate programs served as feeders. The fact that findings contradictory to previous studies conducted, looking at specific factors that correlate to academic achievement, have been reported, means that this study is not only timely but critical. Higher education stakeholders should not only be interested in such findings, but must use it to serve this academic subgroup better.

\section{Definition of Terms}

Academic Achievement - represents performance outcomes that indicate the extent to which a person has accomplished specific goals that are the focus of activities in instructional environments, specifically in school, college, and university (Steinmayr, Meibner, Weidinger, \& Wirthein, 2014). Academic achievement is measured through a student's GPA.

Academic Motivation - Coined by some as "achievement motivation" (Elliot \& Dweck, 2005) is concerned with the study of motivation as is applied to educational experiences, courses, classes, activities, and programs (Deci \& Ryan, 1985; Ryan \& Deci, 2017). It typically manifests itself through a behavior. That behavior is either intrinsically motivated, extrinsically motivated, or amotivated (Deci \& Ryan, 1985). Intrinsic Motivation - Engaging in an activity for the satisfaction the experience brings. People who are intrinsically motivated do so to accomplish, to know and/or to experience stimulation (Vallerand et al., 1992). Deci (1995) noted that it "is the heart of creativity, responsibility, healthy behavior, and lasting change" (p. 9). 
Extrinsic Motivation - Doing an activity as a means to an end. It is an activity that is not done for one's own sake, but in order to obtain an external means of satisfaction such as compliments, good grades, or a reward (Deci \& Ryan, 1985; Vallerand et al., 1992).

Amotivation - Individuals who do not perceive contingencies between outcomes and their own actions. Individuals who are neither intrinsically nor extrinsically motivated (Vallerand et al., 1992).

Academic Self-Efficacy - A student's perceived belief that he/she can accomplish specific academic tasks and goals (Perform Well, n.d.). It is a task-specific selfevaluation that "can enhance feelings of wellbeing" (Bandura, 1994, p. 2).

Mindset (Implicit Theories of Intelligence) - Is the overarching belief about whether or not intelligence is malleable and can change or if it is that with which one is born and is static (Blackwell et al., 2007).

Fixed Mindset (Entity Theory of Intelligence) - Is had by one who believes that learning is based on intelligence only and that ability must be proven. Time is spent documenting how intelligent they are. These are individuals who believe that their success only comes as a result of their talents (Dweck, 2006; Dweck \& Leggett, 1988).

Growth Mindset (Incremental Theory of Intelligence) - Is had by one who believes that learning is based on development, stretching one's ability, and changeability. They believe that through hard work, abilities can be developed. Learning and resilience are key to meaningful accomplishments (Dweck, 2006; "Mindset works," 2017). 
Undergraduate Communication Sciences and Disorders Majors - Students whose major field of study is in the application of biomedical, psychological, and physical principles to the study of the scientific basis, development, and treatment of speech, language, hearing, and cognitive communication problems caused by disease, injury, or disability. It includes instruction in language science, hearing science, speech and voice science, biology of communication, behavioral linguistics, psychology, and applications to the development of diagnostic and rehabilitative strategies and technologies at the undergraduate level (My Majors, n.d.).

Self-concept - refers to the image that an individual has about themselves. It relates not only to ability, but also to overall strengths, weakness, and status (Selfconcept, n.d.)

Self-esteem - an individual's overall subjective evaluation of and attitude toward self. Self-esteem can be positive or negative (McLeod, 2012)

\section{Limitations of the Study}

One limitation of this study was the number of respondents. While the request for participation in the survey was extended to all institutions (42) within Michigan, Indiana, Ohio, and Illinois that offer undergraduate communication sciences and disorders program, only 16 institutions responded with a willingness to participate, resulting in the 210 surveys utilized to complete the study, which may affect the generalizability of this study.

Another limitation concerned the method used in selecting the sample for the study. It is important to note that convenience samples can result in sampling errors and 
decreased credibility due to bias, which could in turn minimize the generalizability of this study.

\section{Delimitations of the Study}

The data was collected from a sample of students enrolled in communication sciences and disorders programs in the Great Lakes States of Michigan, Indiana, Ohio, and Illinois. While the information is important to develop a better understanding of the possible impact of academic achievement, academic motivation, mindset, and selfefficacy on this student group, the sample of those in these states may be skewed and should, therefore, be viewed with caution if attempts are made to generalize the results to all undergraduate communication sciences and disorders students in the United States.

\section{Organization of the Study}

Chapter 2 is a cohesive summary of the literature which summarizes and analyzes the relationships among mindset, academic motivation, self-efficacy, and academic achievement.

Chapter 3 is a detailed focus on the methodology and analysis of the data collected during the study. This chapter gives details as to the research design, instrumentation utilized, and procedures employed to analyze the data.

Chapter 4 presents non-interpretative research findings based on each survey item as responded to by the participants

Chapter 5 presents the conclusion of the study. It includes the discussion of the findings, implications for practice, and future research. 


\section{CHAPTER 2}

\section{LITERATURE REVIEW}

\section{Purpose of Literature Review}

The purpose of the study was to determine the extent to which types of mindset, types of academic motivation, and types of academic self-efficacy are correlated with academic achievement among undergraduate communication sciences and disorders students in selected Great Lakes States.

As a means of providing a better understanding of the nature and attributes of the variables under investigation, an in-depth review of the literature focused on definitions, historical reviews, and summaries of relevant research.

The review of literature included related books, peer-reviewed journal articles, professional literature, and related websites and spans the years from 1977 to the 2017 . Online search tools such as Google Scholars, ask.com, JSTOR, ProQuest, and EBSCO were utilized to complete the review

This chapter was organized by first reviewing academic achievement through the theoretical lens of the EPT that was constructed by Walberg (1984). It also summarized the evolution of academic achievement and its significance to college students. This was followed by a review of the relationship among (1) mindset, through the theoretical lens of implicit theories of intelligence (Dweck \& Leggett, 1998); (2) academic motivation, through the lens of the self-determination theory, (Deci \& Ryan, 1985); and (3) academic 
self-efficacy, through the lens of the social cognitive theory (Bandura, 1977).

Implications for the academic achievement of college students were discussed.

\section{A Historical Overview of Academic Achievement}

Academic achievement is the outcome of education. The product is the tangible proof that one has engaged in active learning (Ward, Stoker, \& Murray-Ward, 1996). In college, this is most often measured through GPA. However, achievement was not always measured in this manner, but on more of a mentorship model (Hartmann, 2012). Students and teachers were in close proximity, and teachers interacted with their students to ensure that learning was occurring.

When students completed their studies, they entered the workforce, not with a diploma, but with the knowledge imparted to them by their teacher. According to Hartmann (2012), around the 19th century at the height of the Industrial Revolution, William Farish, a professor of chemistry at the University of Cambridge, in his attempt to have a higher turnover of students, applied the grading system to education. This system, adopted from factories, was also implemented by Yale College in 1785 where students were ranked by levels based on their performance (Gehrz, 2012). This method did not take long to catch on and was adopted by The College of William and Mary in 1875 and Harvard in 1877 (Durm, 1993; Gehrz, 2012). With this evolution came the adoption of a system called the GPA, which is still in use today.

With an ability to assess the academic achievement of large numbers of students comes the difficulty in being able to provide appropriate interventions when they experience academic failure and/or low achievement.

Responding to these growing concerns among educational stakeholders about the 
efficacy of the grading method and the decline in educational effectiveness overtime, Walberg developed the EPT, which operated on the premise that there are nine factors which influence affective, behavioral, and cognitive learning (McGrew, 2008). Using an industrialized model to explain student achievement, Walberg (2003) summarized that the learning productivity problem is better known and even more acute today. Vastly increased spending and many school reforms resulted in stagnant achievement during the past quarter century, even though children's measured intelligence or capacity for learning increased steadily. Unlike most sectors of the American economy that steadily increase their productivity over time, schools become less rather than more efficient, a serious matter given the size of the education sector and the central and increasing importance of learning in the American economy and society. School productivity or the relation of achievement to costs was $65 \%$ higher in 1970-71 than in 1998-99. (p. 2)

Realizing that this declining area of society impacted almost every facet of society, Walberg (1984) noted that "education may be our largest enterprise in terms of the number of people involved, the value of human time required, and the capital and operating expenditures budgeted" (p. 19).

Walberg $(1984,2003)$ postulated that in order for students to be successful, there must be a balance among student ability, age, motivation, time spent on learning, quality of instruction, home environment, school environment, peer group choices, and time spent out-of-school. Aligning with a balance of aptitude, instruction, and environment, the nine factors are interrelated with varied levels of effect (McGrew, 2008; Walberg, 1984), resulting in favorable achievement outcomes.

The first three noted factors of the EPT are ability, age of development, and motivation, reflecting the characteristics of the student (McGrew, 2008). Walberg (2003) noted that "learning is fundamentally a psychological process; student motivation, instruction, and other psychological factors are the well-established, consistent, and 
proximal causes of learning" (p. 1). The innate student-based influences of academic achievement make motivational factors a critical, yet virtually unknown characteristic factor of this population. Other external factors that may play a strong role must also be acknowledged. Student-driven innate factors such as academic self-efficacy, academic motivation, and mindset are confirmed through research as significant factors that impact student achievement.

\section{A Historical Overview of Mindset}

Mindset, known also as "Implicit Theories of Intelligence," refers to the two opposing frameworks that classify people by how they see and understand intelligence. At either end of the continuum are entity theories of intelligence (fixed mindset) and the incremental theory of intelligence (growth mindset) (Dweck, 2006). As a broader concept of implicit beliefs, Dweck, Chiu, and Hong (1995) claimed that "implicit beliefs influence people's inferences, judgments, and reactions, particularly in the face of negative events" (p. 267).

Mindset is embedded in Kelly's theory of personality and Heider's theory of social perception. Kelly posited that naïve assumptions guide individuals in drawing conclusions about themselves and others (Dweck et al., 1995). This theory emphasized that "a person's processes are psychologically channelized [sic] by the ways in which he anticipates events" (Kelly, 1995, p. 46). Kelly's view was similar to those of Heider (1958) who hypothesized that people's latent beliefs influence the way people are perceived. This concept of implicit theories has been applied to social information (Dweck, et al., 1995), intelligence (Dweck \& Leggett, 1988), as well as other areas of the human experience. The study of human action becomes critical, since people are not able 
to articulate their implicit beliefs fully. This resulted in research investigations of implicit theories of intelligence, also known as "mindset," and their relationship to intelligence and learning (Dweck, 2006).

Dweck $(2000,2006)$ postulated that individuals lay somewhere on the continuum between either the growth mindset described as being "based on the belief that your basic qualities are things you can cultivate through your efforts" $(2006$, p. 7) and the fixed mindset described as "an urgency to prove yourself over and over" (2006, p. 6). Some may assume that one type of mindset is more dominant in our society; however, this is not the case.

According to Dweck \& Molden (2005) both mindsets are equally prevalent with $40 \%$ of children and adults ascribing to the entity theory, $40 \%$ of children and adults ascribing to the incremental theory and most interestingly is the $20 \%$ who are undecided about which they ascribe to or who ascribe to both. Dweck (2015) continued that "students' mindsets—-how they perceive their abilities—played a key role in their motivation and achievement" (para. 1).

\section{A Historical Overview of Academic Motivation}

Theories of motivation have been developed, analyzed, and applied in order to understand people's interests better. In reference to motivation and human development, Deci and Ryan (2002) noted that "endowed with an innate striving to exercise and elaborate their interests, individuals tend naturally to seek challenges, to discover new perspectives, and to actively internalize and transform cultural practices" (p. 3).

The historical path to motivation can be traced to Sigmund Freud, who suggested that two basic needs which exist are life and death (Qadeer, 2009). However, Maslow's 
hierarchical structure of motivation and personality focused on the importance of the lower level needs such as food and nourishment, to growth needs which are achieved when on realizes one's potential. Descartes, a well-known French philosopher and scientist, offered the first identifiable theory of motivation. He believed that the body is an inactive factor in motive, hence, leaving the will as the active factor of motivation (Pakdel, 2013; Qadeer, 2009).

The self-determination theory developed by Deci and Ryan (1985) established that there is a natural tendency toward development and growth. Since that period of its development, motivational approaches based on self-determination theory have been applied to disciplines such as sports, medicine, and education. Concerned more with the type of motivation exhibited (intrinsic, extrinsic, or amotivation) rather than strength of motivation, researchers verified that those who presented with intrinsic motivation were more likely to experience feelings of happiness, satisfaction, and wellbeing (Deci \& Ryan, 2002). Academic motivation is contextual, malleable, and highly individualized. One person can be intrinsically motivated in a specific area and extrinsically motivated in another, while still experiencing characteristics of amotivation in a completely separate area (Schunk, Pintrich, \& Meece, 2008). Motivation can also be enhanced by academic self-efficacy which, when working together, can increase academic achievement (Schunk, 1991).

\section{A Historical Overview of Academic Self-Efficacy}

Coined by Albert Bandura in 1977, the term self-efficacy is defined as "a person's belief in his or her ability to succeed in specific situations" ("Strive together," 2017). Self-efficacy may affect academic motivation, performance, and even persistence. As 
central to social cognitive theory, encompassing a balance of observational learning, social experience, and reciprocal determinism, it is seen as necessary for personality development (Cherry, 2017). Through these foundational theories, the concept of selfefficacy was formed. Just as mindset and academic motivation theorists have extrapolated that these factors impacting academic success are malleable, Bandura (1977) also posited that self-efficacy is malleable and, based on certain factors, can be strengthened or weakened (Dweck, 2010; Mehrabi, Behzadi, Sabouri, \& Alavi, 2016).

Bandura (1977) further postulated that one's self-efficacy beliefs can impact one's outlook related to a situation, impact commitment, and task orientation. Lennon (2010) also noted that self-efficacy is "a cognitive assessment of one's capabilities" (p. 93). This component of social-cognitive theory reinforces the fact that creating a viable path to complete a task is cognitively developed prior to execution, leading to the understanding that those with high levels of self-efficacy most often visualize themselves achieving success in specific task areas. Even if setbacks occur, such high levels of self-efficacy will allow an individual to forge on through adversity (Lennon, 2010).

In a detailed description of the characteristics and common behaviors specific to students with high levels of academic self-efficacy, Bandura (1997) further theorized that these students tend to look at failure as a lack of effort, rather than an academic shortcoming. They commit to task completion, take constructive critique and apply it, and when faced with failure, they increase their effort to forge on to success.

Lennon (2010) found that many studies with an experimental model rather than a correlational model, reported stronger relationships between academic self-efficacy and academic performance. Elementary school children presented with lower levels of 
relevance than high school and college students. Lennon (2010) also noted that when self-efficacy was compared to basic skills such as math and reading, stronger effect sizes were observed. However, there were weaker effect sizes when it was compared to classroom-based measures and standardized assessments. Therefore, based on the aforementioned studies, it can be assumed that a college major or a specific college course could be reliably analyzed for levels of academic self-efficacy.

\section{The Relationship Between Mindset and Academic Achievement}

Numerous studies of implicit theories of intelligence/mindset can be credited to the groundbreaking study of Dweck and Leggett (1988). In an in-depth study and review of previous works, they investigated the relationship between academic motivation and goal orientation in terms of adaptive and maladaptive behavior patterns. The study sought to explain the response patterns of those with a growth mindset and those with a fixed mindset. Dweck and Leggett (1988) discovered that when success was observed, there was very little behavioral difference between the two mindset groups; however, when failure was experienced, differences were clearly indicated. When playing a game that was purposely made to be difficult and in some instances even impossible to complete successfully, those with an entity-fixed mindset verbalized traits of incompetence, such as saying they were not intelligent or not a good problem-solver. Some even became notably anxious. In particular instances, it was reported that some with this mindset even attempted to change the rules of the experimental game. In contrast, those with an incremental growth mindset appeared to embrace the greater challenge. If they did not solve the problem, they did not see it as an inadequacy on their part, but as a "challenge to be mastered" (p. 258). This study also indicated that the two 
mindset types demonstrated differences in self-esteem and self-concept. Dweck and Leggett concluded that those with an entity fixed mindset derived their self-worth from their performance. When failure was experienced, their self-concept and self-esteem suffered. However, those with the incremental growth mindset acquired their self-esteem through pursuing and mastering their learning goals.

Such results would indicate that those with a fixed/entity mindset may find failure crippling and self-stalling, whereas those with a growth mindset demonstrated resilience. They learned from their errors and were willing to work through tasks.

Mindset is also relevant to achievement goals. In a similar study of 291 engineering students in the Philippines, Magno (2012) investigated whether an individual's mindset produced distinct achievement goals. Achievement goals are defined as "competence-relevant aims that individuals strive for in achievement settings" (Elliot, Maier, Binser, Friedman \& Pekrun, 2009; Magno, 2012, p. 32). The achievement goals were noted to be either mastery-approach goals (seeking to learn), masteryavoidance goals (avoiding a task because of feelings of incapability), performance goals (outperforming others), or performance avoidance goals (avoiding performing more poorly than others). The study revealed that both growth and fixed mindsets are adequate predictors of the performance approach to achievement goals. However, growth mindset correlated significantly with the mastery approach. Further, fixed mindset was the only significant predictor for performance avoidance, and neither mindset was significant for mastery avoidance. The findings in this study illustrate that a student's achievement goal orientation did not significantly predict cumulative GPA. However, students' "selfefficacy" and beliefs about their own abilities did influence their academic performance. 
This study revealed some inconsistencies with the relationship between performance goals and academic achievement. It was found that performance goals are sometimes positively related, sometimes unrelated, or sometimes negatively related to academic achievement, reinforcing the view that one's ability to persevere is related to one's thought process about personal intelligence.

Mindset can also impact academic content areas in different ways. For example, some individuals may present a growth mindset when it relates to their abilities in math, but they may also present a fixed mindset in relation to their abilities in anatomy and physiology. Leondari and Gialamas (2002) conducted a study on 451 elementary and adolescence school children in Northern Greece. The study explored the relationship between mindset, goal orientation, perceived competence, and school achievement. Results showed that students demonstrated a mixture of different achievement goals being pursued, while at the same time pointing to a simultaneous occurrence of several experiential effects.

The researchers also postulated that as students move from elementary school age to early adolescence, their academic motivation and achievement declined. This study offered vital information related not only to mindset and achievement, but also to the malleability of such factors. A limitation not cited in this study was the possible impact of factors such as adolescent social peer pressures (Johnson, 2000) which may have contributed to the noted decline in academic achievement and motivation when students entered middle school. Such factors as noted are addressed by Walberg (1984) through his application of the EPT which emphasized that many factors contributed to and impacted academic achievement. 
Gondida, Kiosseoglou, and Leondari (2006) contended that the causal effects of mindset may be multifaceted and linked to domains, and not necessarily to academic achievement. The results of their study revealed that academic achievement was not related to mindset, but rather to perceived competence in one's ability.

Diseth et al. (2014) investigated the relationships among mindset, intelligence, academic achievement, motivation, and self-esteem in a sample of 2,062 Norwegian 6th and 8th graders. The results of their study revealed that (1) there was a positive correlation among growth mindset, self-esteem, and self- efficacy (self-beliefs); (2) selfefficacy was a better predictor of performance than self-esteem; and (3) there were some positive relationships between self-esteem and self-efficacy across the grades and gender. However, some subtle differences were apparent, i.e., (1) self-beliefs were lower among 8th-grade subjects than among 6th-grade subjects; (2) girls performed significantly better than boys in the area of academic achievement, but presented with lower levels of selfesteem and academic self-efficacy in comparison to boys; and (3) 8th-grade girls demonstrated lower self-esteem in comparison to 6th-grade girls.

These findings are similar to those previously noted by Leondari and Gialamas (2002) which confirmed that as students advanced in grades, academic motivation and academic achievement declined. Leonardi and Gialamas (2202) also noted that fixed mindset did not negatively impact the components of self-beliefs, but it negatively impacted academic achievement. Diseth et al. (2014) suggested that children who felt that one is born with a certain level of intelligence that cannot expand or grow also tended to demonstrate lower levels of academic achievement than their peers, who believe that intelligence is malleable. However, these same children reported rather high 
levels of self-belief or self-efficacy, leading one to surmise as did Chemers, $\mathrm{Hu}$, and Garcia (2001), that high self-efficacy, while related to achievement, cannot always explain high levels of achievement. Furthermore, achievement may also be based on other factors such as working hard, time management, strong support systems, and inspiring and dedicated instructors (Strang, 2015).

Longitudinal studies are ideal when considering the long-term impact and effect of certain variables such as mindset, academic self-efficacy, and academic motivation. Robins and Pals (2002) used a longitudinal design to investigate students over the four years of college. Achievement and goal orientation among other constructs were studied, utilizing high school GPA, GPA changes over time, SAT scores, and questions about goal orientation that could be deemed more performance-based or learning/masterybased. Robins and Pals (2002) found very little change in the ascribed mindset over time during the college years. However, these researchers also found that self-esteem for those with a growth mindset increased and self-esteem for those with a fixed mindset decreased. These factors were both mediated by goal orientation (performance orientation versus mastery orientation). Robins and Pals (2002) concluded that mindset which is stable by college correlates with the growth and/or decline of self-esteem.

In the Diseth et al. (2014) study, when the gender variable was factored in, it was found that females, while reporting higher achievement levels, reported lower self-esteem and self-efficacy. Research has also confirmed a link between academic achievement and academic motivation that could further lead to the understanding of student academic achievement and/or under-achievement (Hegarty, 2010; Isiksal, 2010; Vallerand et al., 1992). 


\section{The Relationship Between Academic Motivation and Academic Achievement}

There is no doubt that academic motivation can significantly impact academic outcomes, persistence, and academic success. Vallerand et al. (1992) noted that "Indeed, much research has shown motivation is related to various outcomes, such as curiosity, persistence, learning, and performance" (p. 1004). One measure that has been used to study academic motivation is the Academic Motivation Scale (AMS). Renamed and adapted from the French Version Echelle de Motivation en Education, it is divided into three key major areas of intrinsic motivation, extrinsic motivation, and amotivation, and is employed to measure academic motivation. This measure is supported by the selfdetermination theory, which is concerned with motivation and personality traits that drive people's choices and inherent growth through self-motivation. Intrinsic motivation, extrinsic motivation, and amotivation are further divided and utilized to gain a better understanding of what motivates the student (Ryan \& Deci, 2000; Vallerand et al., 1992).

Vallerand et al. (1992) described intrinsic motivation as engagement in an activity or learning experience for the gratification and fulfillment it brings. Extrinsic motivation was described as a form of motivation in which activities are engaged in as "means to an end and not for their own sake" (Deci, 1975, p. 23). Finally, amotivation was described as a lack of motivation when one is neither intrinsically nor extrinsically motivated. Individuals who are amotivated are often plagued by feelings of inadequacy and inability (Vallerand et al., 1992).

Hegarty (2010) used the AMS to investigate graduate students' levels of academic motivation. Hegarty's sample consisted of 240 business and education graduate students from a northeast United States university. The study, which had a larger sample of 
females than males (154:86), found that the graduate students presented with greater levels of extrinsic motivation on the continuum levels of motivation. The mean for this study was 7.30 which was considerably lower than the mean of 10 , typically reflected in other studies. The results revealed that graduate students have higher levels of extrinsic motivation than elementary, high school, and undergraduate students, leaving one to conclude that graduate students' motivation is much more performance-based than mastery-based. Hegarty mentioned that one limitation of the study was its generalizability or external validity, since the sample population was small and confined to students from one institution.

In an attempt to understand better which type of motivation may impact a student's success or failure, Maurer et al. (2012) studied a group of students who were enrolled in an allied health course. He found that there was a significant relationship between intrinsic motivation, amotivation, and student success or failure. Students with higher levels of amotivation tended toward failure in the course, while students with higher intrinsic motivation tended toward success. Extrinsic motivation was high in this population. However, no significant relationship between extrinsic motivation and academic success was found.

Isiksal (2010) sought to determine whether there were significant differences between Turkish and American students' intrinsic motivation, extrinsic motivation, amotivation, and self-concept. Differing from self-efficacy, self-concept refers to the image that individuals have about themselves. It relates not only to ability, but to overall strengths, weaknesses, and status (Self-concept, n.d.). The study did not merely look at the comparative data between the two groups, but also tested for significance based on 
number of years in schools. The US participants ( $76 \%$ female) were from various undergraduate majors with a racial demographic of $89.8 \%$ White/Caucasian, $3.9 \%$ African-American, $2.8 \%$ Asian, and 1\% Hispanic. The Turkish participants (47\% female and 53\% male) also represented various academic majors. The academic levels represented were freshman, sophomore, junior, and senior.

Results of the study confirmed that US students had higher levels of extrinsic motivation than their Turkish peers. However, the US students' level of extrinsic motivation declined as they progressed through undergraduate programs, but there was an increase in their intrinsic motivation. This could be explained by the fact that as the students progressed, they developed more personal self-interest in the topics being studied. In the area of self-concept, US students had higher levels when compared to their Turkish peers.

These findings contradicted Hegarty's (2010) study, which showed that US students exhibited greater levels of extrinsic motivation at the undergraduate levels. Because of the malleable nature of academic motivation, as well as its variability across various subjects, content areas, and activities (Deci \& Ryan, 1985), such findings are possible.

The results of Isiksal's (2010) study leave obvious questions about the cultural variation between the two groups, as well as the age levels of those in the various programs. It was unclear whether the typical undergraduate students in the United States were comparable in age to undergraduate Turkish students.

Using a descriptive design, Durso, Da Cunha, Neves, and Teixeira (2016) studied the level of student motivation to search for and pursue a graduate degree. The study 
consisted of accounting and economics students from public universities in Brazil. The researchers hypothesized that accounting students were less intrinsically motivated to pursue a graduate degree in accounting, when compared to their peers pursuing degrees in economics. They intended to utilize these findings to justify the chronic shortage of accountants with advanced Master and/or Doctoral level degrees in the area of accounting. The results of the study revealed that there were no statistically significant differences between the two groups, thereby rejecting the research hypothesis. Durso, DaCunha, Neves and Teixeira noted that "the reason why there are fewer students in accounting who pursue a Master's degree is not related to motivation to keep studying" (p. 255). The study concluded that those in the workforce in accounting were more selfdetermined to pursue a graduate degree than their peers who were not a part of the workforce.

Mehrabi et al. (2016) hypothesized that academic motivation can be adjusted through cognitive behavioral methodologies. They investigated the malleability of intrinsic motivation by conducting a pre-test/post-test study of 120 Persian nursing students. The participants, along with a control group, completed a Persian version of the AMS. As expected, there was no difference at the point of pre-test between the control group and the test group. The subjects then engaged in cognitive behavioral therapy sessions that addressed automatic thought prevention, cognitive reconstruction, stress management, and communication management. The subjects were then retested and found to improve their intrinsic motivation significantly. It was also noted that after the one-month post intervention period, there was very little change to the post-test results. 
These researchers concluded that academic motivation is malleable if appropriate interventions are applied.

Investigating academic motivation among students in undergraduate and graduate institutions provides meaningful outcomes for educational stakeholders regardless of the fact that the sample populations in a majority of studies conducted have been predominantly White/Caucasian. This, however, is consistent at all academic levels researched from elementary to graduate school (Cokley 2003; Hegarty, 2010; Vallerand et al., 1992), making the shift of generalizing findings to the Non-White (ethnically diverse) students somewhat challenging.

While the study conducted by Durso et al. (2016) included Brazilian students who are citizens of a country whose population is reported to be over 50\% African descent (Phillips, 2011), there are cultural components that are vastly different from that of the Black/African-American population of the United States. According to the Communication Sciences and Disorders Education Trend Data Undergraduate Programs (n.d.), at least $27 \%$ of communication sciences and disorders students are non-White. However, this small percentage of students still makes up a critical cross-section of the US population. Very little data is available on the academic motivation of Non-White students in college, hence the need for researchers to construct research studies in academic environments intentionally where there is a strong representation of minority student groups.

Long, Monoi, Harper, Knoblauch, and Murphy (2007) examined the relationship between self-efficacy and motivation in a group of African-American 8th- and 9th-grade students. Operating on Bandura's premise, Schunk (1991) noted that "self-efficacy 
affects an individual's choice of activities, effort, and persistence" (p. 208), this study examined the students while they transitioned from middle to school to the higher academic demands of the high school. The sample consisted of $87 \%$ African-American, 10\% Caucasian students, and 3\% which included Hispanics, Native Americans, and Asians. The researchers found that among the African-American population of 8th-grade students, domain interests and achievement were lower and more insignificant than with 9th graders. African-American students presented with moderate levels of the motivational variables (self- efficacy, domain interest, and personal goal orientation). They also presented lower levels of the motivational study variables when they entered high school. African-American students also demonstrated higher levels of self-efficacy to domain interests. This was found to be lower in their White peers.

The social disparities of both groups cannot be ignored and should be considered a possible contributing factor to any observed differences. African-American students are often made to adopt an "oppositional identity" (Long et al., 2007, p. 214). This phenomenon is noted when the students are seen negatively by their peers and social group for demonstrating academic interests. Long et al. (2007) noted that some students may be able to maneuver through these issues by behaving in a socially acceptable manner toward academic endeavors while still performing adequately. It is likely that because of the school programming, students who had a vocational interest may have experienced difficulty in nurturing it. When compared to the typical undergraduate college student who is more likely to be pursuing a field of interest, elementary/high school students have fewer choices and academic options that may truly have peaked their interest (Long et al., 2007). 
Further investigation into academic motivation and its effects on the AfricanAmerican student is addressed by Cokley (2003), who was interested in looking at motivation as an explanation for the African-American student's underachievement. Noting that conflicting levels of extrinsic motivation can adversely affect levels of intrinsic motivation (Deci \& Ryan, 1985). Cokley (2003) confirmed (p. 536) that the AMS was validated and utilized in the assessment of the academic motivation of students identified as predominantly White/Caucasian (Hegarty, 2010; Vallerand et al., 1992).

The participants in Cokley's study consisted of 687 students (396 AfricanAmerican and 291 Caucasian) attending three historically Black colleges and universities and one predominately White/Caucasian college and/or university. Along with the AMS, the researchers utilized the Academic Self-Concept Scale, Rosenberg Self-Esteem Scale, and academic performance. The study found that African-American students at historically Black colleges and universities reported higher intrinsic motivation and selfconcept than African-American participants attending predominantly White colleges and universities. The study also revealed that while African-American students at predominantly White colleges and universities reported higher extrinsic motivation and self-esteem than White students at predominantly White colleges and universities, they reported lower GPAs.

Research has confirmed that further investigations of the link between academic achievement and academic self-efficacy could further lead to the understanding of student academic achievement and/or under-achievement (Chemers et al., 2001; Kahn, 2013). 


\section{The Relationship Between Academic Self-Efficacy and Academic Achievement}

Chemers et al. (2001) conducted a longitudinal study of college freshman that examined the impact of self-efficacy and optimism on academic performance, stress, health, and persistence, specifically academic expectations. While the study questionnaire was sent to over 1600 college freshmen at the University of California, Santa Cruz, only 373 and 256 students respectively responded (as noted above) during both waves of the survey.

The gender distribution was about $80 \%$ female and $20 \%$ male. The racial distribution was approximately 57\% White, 15\% Hispanic, 16\% Asian and 14\% other. Academic self-efficacy was measured by utilizing an eight-item Likert scaled measure that would eventually become the Academic Self-Efficacy Rating Scale. Chemers et al. (2001) noted that "the measure was designed to reflect a variety of specific skills pertinent to academic achievement, including scheduling of tasks, note taking, test taking, and researching and writing papers, and included general statements regarding scholarly ability" (p. 59). To test optimism, the Life Orientations Test (Scheier \& Carver, 1985) was utilized.

The results of the study indicated a strong correlation between self-efficacy and optimism in the success and adjustment of the first-year college students specific to their academic performance. Self-efficacy was also directly linked to academic expectations and was described as the student's "expectations for future academic performance" (Scheier \& Carver, 1985, p. 59). The data revealed strong indications that high school academic self-efficacy was a predictor of high college self-efficacy. Scheier and Carver (1985) concluded that 
students who enter college with confidence in their ability to perform well academically do perform significantly better than do less confident students. Likewise, students who have higher expectations for academic success show higher performance. Some of these effects may be caused by superior academic ability, which could be related to both confidence and performance. (p. 61)

This study suggests that previous academic experiences, as well as current experiences played a significant role in academic self-efficacy.

In a comparable 2013 pilot study, Kahn considered the relationship between academic self-efficacy, coping skills, stress, and academic performance. Sixty-six undergraduate students consisting of $74 \%$ females and $26 \%$ males, $2 \%$ Black/AfricanAmericans, 3\% Hispanics, 9\% bi-racials, and $86 \%$ White participated in the study. Another question the study sought to answer was whether there was an association between academic self-efficacy and academic performance. The Academic Self-Efficacy Scale was utilized to measure self-efficacy. The researcher utilized the Pearson Product Moment Correlation to explore the link between the two variables and concluded that there was a relationship between academic self-efficacy and performance, specifically GPA. This study along with Chemers et al.'s (2001) findings clearly leads to positive correlation between students' academic performance (GPA) and academic self-efficacy.

While Chemers et al. (2001) purported that a positive relationship exists between self-efficacy and academic achievement, they did not suggest possible reasons for this correlation. Tang and Westwood (2007), however, attempted to correlate levels of selfefficacy with self-reported reasons for worrying. The study attempted to investigate what self-reported issues were impacting achievement. It also attempted to determine whether students had positive self-efficacy beliefs based on various situations, and if there was a difference in the self-efficacy of higher- and lower-achieving students. It also sought to 
investigate the relationship between self-efficacy, academic achievement level, and level of worry. The researchers found that (1) a large number of students reported experiencing moderate levels of worry; (2) self-efficacy ratings were fairly high; (3) lower-achieving students reported lower self-efficacy in areas such as concentration, meeting the expectations of their teachers, and reliability, but this was not statistically significant when compared to higher achieving students; and (4) there was no significant association found among self-efficacy, degree of worry, and academic achievement.

Several important limitations were noted, including the appropriateness of using a qualitative, rather than a quantitative model to measure worry. The researchers noted that the results of the study may have been impacted by the encapsulation of both academic and non-academic measures of self-efficacy.

Ozer and Akgun (2015) conducted a study concerning the effects of irrational beliefs on academic motivation and self-sufficiency. They hypothesized that "irrational beliefs have various effects on certain characteristics of the students" (p. 1289). They studied a sample group of 161 second- and third-year post-high school students studying to become teachers in the areas of computer technology and instructional technology. The independent variable (irrational beliefs) and the dependent variables (academic motivation and academic self-sufficiency) were analyzed through a cross-sectional approach. All three variables were measured by utilizing three subject-specific surveys. The study confirmed a positive relationship between irrational beliefs and academic motivation. This means that when levels of academic motivation increased, irrational beliefs also increased. Ozer and Akgun (2015) also confirmed that when academic motivation increased, there was a moderate increase in academic self-sufficiency. 
However, there were no significant findings on the relationship between irrational beliefs and academic self-sufficiency. Ozer \& Akgun (2015) claimed that their study was not meant to imply that one variable caused the other, but to show that there was a descriptive relationship between the variables.

\section{Brief Summary of Literature}

This review of literature provided evidence that confirmed relationships among mindset, academic motivation, academic self-efficacy, and academic achievement. There was little difference between mindset types when students were experiencing success (Dweck \& Leggett, 1988). However, when failure occurred, students with a fixed mindset became paralyzed and tended to be critical of their intelligence and abilities.

The link between self-efficacy and effect of prior achievement was also key to understanding the impact of a fixed mindset on academic performance. If students avoid activities that are difficult, it may lead them to exhibit a false sense of self-efficacy.

Studies have investigated important links between mindset and academic selfefficacy, and their impact on motivation (Dweck, 2006; Schunk, 1991). One's perceived competence (self-efficacy) may be affected by prior academic achievement and may also predict future achievement (Chemers et al., 2001).

Prior academic achievement has also been found to mediate mindset. One may, therefore, conclude from research that self-efficacy and mindset are linked to motivation and academic achievement. 


\section{CHAPTER 3}

\section{METHODOLOGY}

\section{Introduction}

The purpose of this study was to investigate the extent to which academic achievement is related to mindset, academic motivation, and academic self-efficacy in the population of communication sciences and disorders students at the undergraduate level in selected Great Lakes States. The dependent variable in the study was academic achievement. The independent variables examined were mindset, academic motivation, and academic self-efficacy.

This chapter consists of a detailed description of the research design employed, the population and method of sample selection, instrumentation and validity, procedure and data analysis of this study. Chapters 1 and 2 laid the groundwork for the appropriate use of the survey method and the instrumentations described below.

\section{Research Questions}

The following questions will focus on factors relating to the academic achievement of students pursuing an undergraduate degree in the field of communication sciences and disorders at selected Great Lakes States Universities:

Research Question 1: What are the types of mindset, types of academic motivation, types of academic self-efficacy, and levels of academic achievement 
described by students pursuing an undergraduate degree in the field of Communication Sciences and Disorders at selected Great Lakes States universities?

Research Question 2: To what extent are mindset, academic motivation, and academic self-efficacy related to the academic achievement (GPA) of students pursuing an undergraduate degree in the field of Communication Sciences and Disorders at selected Great Lakes States universities?

\section{Research Design}

The study employed a quantitative correlational design using an online survey questionnaire methodology. Trochim (2006) stressed the importance of survey research as an important area of measurement in applied social research. The broad area of survey research encompasses any measurement procedure that involves asking questions of respondents. A "survey" can be anything from a short paper-and-pencil feedback form to an intensive one-on-one in-depth interview. Conducting online surveys are low-cost, time-saving, convenient, and offer good statistical significance. However, such methods can be inflexible, have limited respondent availability and sampling, and can be inappropriate for controversial issues (Research methodology, 2016; Trochim, 2006; Wyse, 2012). Utilizing such a method for this current study allowed for data collection over a large geographical region in a rather short period of time. Such methods of data collection are also appropriate for the correlational design employed for this research.

Convenience sampling was employed to study the relationship of academic achievement to mindset, academic motivation, and self-efficacy of undergraduate communication sciences and disorders students at selected universities in the Great Lakes States of Michigan, Indiana, Ohio, and Illinois. There are advantages and disadvantages 
to this method of data collection. Convenience sampling allows for research to be conducted with greater ease and less cost, as well as allowing for accelerated data collection. However, there can be an increase in sampling errors, decreased credibility as well as greater levels of bias (Research methodology, 2016).

Correlational research is defined as a measure of the relationship of two variables. This type of research attempts to determine whether there is a relationship between and within selected variables. Furthermore, correlational research can be used for the purpose of prediction, validity, reliability, and theory verification (McLeod, 2008).

\section{Population and Sample}

The target population for this study was undergraduate communication sciences and disorders students from the Great Lakes region of the United States (Which states border the Great Lakes?, 2017). Undergraduate communication sciences and disorders programs are structured to equip students with foundational knowledge and skills in both speech-language pathology and audiology, preparing them for pursuit of advanced degrees in either profession (ASHA, 2017).

The sample for this study was selected from the Great Lake States of Michigan, Indiana, Ohio, and Illinois. Moinester and Gottfried (2014) noted that "estimating sample size before conducting a study, or at the early stage of a study, is scientifically important in order to maximize the probability to detect any existing significant correlations" (p. 124). ASHA (2017) reported that in 2015, there was a total of 40,587 undergraduate students in the United States who declared communication sciences and disorders as their major, based on undergraduate program reporting, with a five-year average of 40,528. Within the four states included in this study, there were 42 
universities that offered undergraduate communication sciences and disorders programs, reporting a total of 5,540 undergraduate students in 2015, with an estimated sample size of 277 (.5\% of the population). Sixteen of the 42 institutions agreed to participate in the study, and 215 undergraduate communication sciences and disorders students completed the survey.

\section{Instrumentation}

The instrument utilized for this study was comprised of four sections with a total of 75 items (see Table 1). It was created in the Class Climate version V7.0 licensed to Andrews University. Section one comprised of self-reported demographic information including race, age, major, class standing, and GPA. Part two measured levels of the mindset (Dweck, 2010; Dweck \& Leggett, 1988), part three measured academic motivation utilizing the AMS (Vallerand et al., 1992), while part four measured levels of academic self-efficacy, utilizing the College Academic Self-Efficacy Scale (CASES) (Owens \& Froman, 1988). Sections two, three, and four utilized a Likert scale ranging from 1 to 7 with 1 reflecting the least confident/strongest level of disagreement and 7 the most confident/strongest level of agreement. These instruments were chosen because of their consistent vast use and reference throughout research literature, as well as their strong validity and reliability data (Blackwell et al., 2007; Dweck et al., 1995; Fairchild, Horst, Finney, \& Barron, 2005; Owens \& Froman, 1988; Vallerand et al., 1992; Walter, Shenaar-Golan, \& Greenberg, 2015). Table 1 outlines the distribution of the survey instrument. 
Table 1

Survey Item Distribution

\begin{tabular}{lll}
\hline Survey Section & \# of items & Range of Items \\
\hline Demographic Information & 6 & $1-6$ \\
Mindset & 8 & $7-14$ \\
Academic Motivation & 28 & $15-42$ \\
Academic Self-Efficacy & 33 & $43-75$ \\
Total Items & 75 & \\
\hline
\end{tabular}

Developed by Carol Dweck (2010), the Implicit Theories of Motivation Measures analyzes whether an individual has more of a fixed or a growth mindset. The eight-item measure utilizes a six-point Likert scale ranging from strongly disagree to strongly agree. For the purposes of this study and to offer continuity of least to most, the scale was reordered from 1 to 7 with 1 indicating "strongly disagree" and 7 "strongly agree." The internal reliability of this measure was .78 in the first study with a mean of 4.45 and a standard deviation of .97 . The test-retest reliability was .77 when conducted two weeks later (Blackwell et al., 2007). The scale also demonstrated strong construct validity "with scores predicting theoretically meaningful relationships with a range of variables" (DeCastella \& Byrne, 2015, p. 10). Dweck et al. (1995) further confirmed that the scale is unaffected by factors such as intellectual ability, political beliefs, or social desirability.

Originally normed and validated in French (and named the Echelle de Motivation en Education-EME) the AMS was translated into English and validated by Vallerand et al. (1992). The reliability of the instrument was assessed and found to be similar to the French version with an internal consistency of varying values from .76 to .82 . In this study, the subtest for the identification scale indicated greater levels of variance. Testretest results were also judged to be high with what was considered "acceptable variance 
at pretest of .71 to .83 with a mean test-retest correlation of .79" (p. 1012). These results confirm internal consistency. The test of validity was also positive with a replication of the original factor analysis of the French version of the scale. The confirmatory factor analysis of the seven subscales found that the model fit the data with the Normed Fit Index of .93, Adjusted Goodness of Fit Index of .91, and the Goodness of Fit Index of .94 (p. 1011).

The CASES was developed based on Bandura's 1977 self-determination theory of self-efficacy and its role in academic performance, sports ability, and even socialization (Owens \& Froman, 1988). Reliability of this scale was determined through a testing of two separate groups of students with an alpha internal consistency estimate of .90 and.92 respectively. The authors also noted that the 8-week stability estimate was .85 (Owens \& Froman, 1988, p. 4). Concurrent validities were measured looking at frequency of performing each task, as well as enjoyment of each task. In each study, it was determined that academic self-efficacy was a better determinant than GPA, with GPA estimated at .40 for frequency of task and self-efficacy at .78. When measuring enjoyment, GPA was estimated at .38 and self-efficacy estimated at .72.

A Cronbach alpha measure of internal consistency reliability was performed for this study for growth mindset, fixed mindset, intrinsic motivation, extrinsic motivation, amotivation, and academic self-efficacy. Table 2 indicates that the Cronbach alpha for each measure demonstrated good to excellent internal consistency with a range between .83 and .99 . A Cronbach alpha internal consistency above .7 is acceptable (Cronbach's Alpha: Simple Definition, Use and Interpretation, 2017). 
Table 2

Reliability for Mindset, Academic Motivation and Academic Self-Efficacy $(N=210)$

\begin{tabular}{llll}
\hline SubScale & Cronbach's Alpha & Internal Consistency & \# of Items \\
\hline Growth Mindset & .889 & Good & 4 \\
Fixed Mindset & .884 & Good & 4 \\
Intrinsic Motivation & .991 & Excellent & 12 \\
Extrinsic Motivation & .830 & Good & 12 \\
Amotivation & .888 & Good & 4 \\
Academic Self- & .942 & Excellent & 33 \\
efficacy & & & \\
\hline
\end{tabular}

\section{Procedure}

Once the Andrews University Institutional Review Board (IRB) approval was obtained, the following procedure was employed as a means of completing the research for this study:

1. Beginning in Early April of 2017, the IRB for each institution that offers an undergraduate communication sciences and disorders programs at Great Lakes States institutions in Michigan, Indiana, Ohio, and Illinois were contacted via email requesting their assistance in the completion of this study. The IRB department responded that the institutions were "not engaged." This meant that official IRB approval from the institutions was not needed if IRB approval from Andrews University was obtained.

Once the institutions agreed to allow their students to participate in the study, a contact person from the communication sciences and disorders department of each university was identified. Once an affirmative response was received, a letter detailing the purpose of the study was forwarded. Once a response was received, the invitation to participate in the study along with a link for the survey was forwarded via email for distribution to their students. 
2. The link, once opened, gave a brief non-leading explanation of the purpose of the study. Detailed instructions as to how to complete the survey was given along with the assurance that they could opt out of the study at will at any time. They were also assured that the survey results were anonymous.

3. The collection of data ended during the first week of May 2017, giving participants approximately four weeks to complete the survey. Based on the willingness of the contact person at each institution, an email reminding them to respond to the survey was sent to each student.

\section{Data Analysis}

The data collected was transferred from Class Climate and analyzed using the latest version of the Statistical Package for Social Science (SPSS). Descriptive statistics were analyzed and reported to include mean, standard deviation, frequency, and skewness.

To determine the percentage of students who responded to each dimension/category of the Likert scale (viz., disagree/not confident, neutral, agree/confident of mindset), academic motivation and academic self-efficacy were also reported. The Spearman Rank Correlation was used to analyze ordinal variables (Spearman's Rank-Order Correlation using SPSS Statistics, n.d.), and was used to determine the strength and direction of the association between the variables. The final analysis was performed using categorical regression (CATREG), which is utilized to analyze categorical data by assigning a numerical value to the categories (CATREG, 2012). 


\section{Summary}

The study investigated the extent to which types of mindset, types of academic motivation, and levels of self-efficacy are correlated with academic achievement among undergraduate communication sciences and disorders students in selected Great Lakes States. The variables were measured through self-reporting demographic information that included GPA as a measure of achievement; CASES (Owens \& Froman, 1988); AMS (Vallerand et al., 1992); and Implicit Theories of Intelligence Measure (Dweck, 2010).

Emailed links were forwarded to a designated individual in the undergraduate communication sciences and disorders programs for dissemination to the participants. The survey was created and distributed through Class Climate version V7.0 licensed to Andrews University. Each institution's link was coded as a means of tracking the number of responses obtained from each university. The data was then transferred into SPSS for analysis. 


\title{
CHAPTER 4
}

\begin{abstract}
ANALYSIS OF DATA
The purpose of the study was to determine the extent to which types of mindset, types of academic motivation, and levels of academic self-efficacy are correlated with academic achievement among undergraduate communication sciences and disorders students in selected Great Lake States. This chapter offered a systematic examination of how the data were analyzed to answer the research questions:

Research Question 1: What are the types of mindset, types of motivation, types of academic self-efficacy, and levels of academic achievement described by students pursuing an undergraduate degree in the field of communication sciences and disorders at selected Great Lake States universities?

Research Question 2: To what extent are mindset, academic motivation, and academic self-efficacy related to the academic achievement of students pursuing an undergraduate degree in the field of Communication Sciences and Disorders at selected Great Lake States universities?
\end{abstract}

\section{Description of the Sample}

The research included undergraduate communication sciences and disorders students from colleges and universities within the Great Lakes States of Michigan, Indiana, Ohio, and Illinois (see Table 3). Two hundred and fifteen surveys were returned. 
However, due to the incomplete nature of some of the surveys, five were eliminated, leaving 210 viable surveys.

\section{Demographic Information}

The participants in this study were $96.7 \%$ female (see Table 3 ). The gender distribution was consistent with the reported demographic population of undergraduate communication sciences and disorders students from the Great Lakes States of Michigan, Indiana, Illinois, and Ohio. The Communication Sciences and Disorders Education Survey Data Reports (2017) noted that in the 2014-2015 academic year, $96.5 \%$ of students were female. Eighty percent of the respondents were White/Caucasian, 9\% Hispanic, 5\% Asian, and 5\% Black/African-American. The total of non-White respondents was $19 \%$. The racial/ethnic distribution of this current study is similar to the reported demographic population of undergraduate communication sciences and disorders students for the states of Michigan, Indiana, Illinois, and Ohio.

The Communication Sciences and Disorders Education Survey Data Reports (2017) revealed that in the 2014-2015 academic year, $87 \%$ of students within the four states were White/Caucasian, with $13 \%$ reported as non-White. Seventy-nine percent of the participants were between the ages of 18 and 21, followed by those between the ages of 22 and $26(19.5 \%$ ) (see Table 3). The college level demographic revealed that $38 \%$ were senior, $24.4 \%$ were juniors, $21.5 \%$ were sophomores, and $16.3 \%$ were freshmen. Forty percent of the participants in this current study attended institutions in Michigan, $35.7 \%$ attended institutions in Indiana, followed by $12.4 \%$ ) in Ohio, and $11.9 \%$ in Illinois. While all 42 institutions within the four states that offer communication sciences and disorders programs were contacted, a total of 16 responded and ultimately decided to 
Table 3

Undergraduate Communication Sciences and Disorders Students' Demographic $(N=210)$

\begin{tabular}{|c|c|c|}
\hline Variable & $N$ & $\%$ \\
\hline \multicolumn{3}{|l|}{ Gender } \\
\hline Male & 5 & 2.4 \\
\hline Female & 205 & 97.6 \\
\hline Total & 210 & 100.0 \\
\hline \multicolumn{3}{|l|}{ Age Range } \\
\hline $18-21$ & 166 & 79.1 \\
\hline $22-25$ & 41 & 19.5 \\
\hline $26+$ & 3 & 1.4 \\
\hline Total & 210 & 100.0 \\
\hline \multicolumn{3}{|l|}{ Race } \\
\hline Asian/Pacific Islander & 11 & 5.3 \\
\hline Black/African-American & 11 & 5.3 \\
\hline Hispanic/Latino & 18 & 8.6 \\
\hline Native American & 1 & 0.5 \\
\hline White & 168 & 80.4 \\
\hline Total & 210 & 100.0 \\
\hline \multicolumn{3}{|l|}{ College Level } \\
\hline Freshmen & 34 & 16.3 \\
\hline Sophomore & 45 & 21.5 \\
\hline Junior & 51 & 24.4 \\
\hline Senior & 79 & 37.8 \\
\hline Total & 209 & 100.0 \\
\hline \multicolumn{3}{|l|}{ State } \\
\hline Michigan & 84 & 40.0 \\
\hline Ohio & 26 & 12.4 \\
\hline Indiana & 75 & 35.7 \\
\hline Illinois & 25 & 11.9 \\
\hline Total & 210 & 100.0 \\
\hline \multicolumn{3}{|l|}{ GPA } \\
\hline Below 2.59 & 3 & 1.4 \\
\hline $2.6-3.00$ & 12 & 5.7 \\
\hline $3.1-3.59$ & 62 & 29.5 \\
\hline $3.6-4.00$ & 133 & 63.3 \\
\hline Total & 210 & 100.0 \\
\hline
\end{tabular}


participate in the study. Sixty-three percent of participants reported a GPA range of 3.6 to 4.0 with $29.5 \%$ reporting GPAs ranging from 3.1 to 3.59 (see Table 3).

\section{Research Questions}

\section{Research Question 1}

What are the types of mindset, types of academic motivation, types of academic self-efficacy, and levels of academic achievement described by students pursuing an undergraduate degree in the field of Communication Sciences and Disorders at selected Great Lakes States universities?

To answer this question a total mean score for each factor was calculated. As noted above, a sample size of 210 undergraduate communication sciences and disorders students completed the surveys, which were made up of demographic scales, the AMS, the CASES, and the measures of levels of mindset, using a 7-point Likert scale. The 7point Likert scale ranged from "strongly disagree" to "strongly agree" for testing levels of mindset and academic motivation and "no confidence" to "very confident" for levels of academic self-efficacy. The mean range of each independent variable was organized by the percentage of participants whose responses were rated as low (means $=1.0-3.99$ ), medium $($ means $=4.0-4.99)$, and high $($ means $=5.0-7.0)$ for each independent variable. This information along with the means, standard deviations, and minimum and maximum means were reported.

\section{Mindset}

Growth mindset has a reported mean of 4.80 and a standard deviation $(S D)$ of 1.07 (see Table 4), with a skewness of $+/-1(S E=.168)$. Fixed mindset has a reported 
Table 4

Descriptive Statistics of Independent Variables $(N=210)$

\begin{tabular}{lccccc}
\hline Variables & Mean & $S D$ & Min & Max & Skewness \\
\hline Types of Mindset & & & & & \\
$\quad$ Growth Mindset & 4.80 & 1.07 & 1.25 & 7.00 & -.420 \\
$\quad$ Fixed Mindset & 3.16 & 1.23 & 1.00 & 7.00 & .420 \\
& & & & & \\
Types of Motivation & & & & & \\
$\quad$ Intrinsic Motivation & 5.22 & .90 & 2.58 & 7.00 & -.334 \\
$\quad$ Extrinsic Motivation & 5.90 & .69 & 3.91 & 7.00 & -.684 \\
Amotivation & 1.62 & .85 & 1.25 & 4.75 & 1.71 \\
& & & & & \\
$\quad \begin{array}{l}\text { Academic self- } \\
\quad \text { Efficacy }\end{array}$ & 5.08 & .83 & 2.67 & 7.00 & -.062 \\
\hline
\end{tabular}

Standard Error $=.168$

mean of 3.16 and a $S D$ of 1.23 , with positive skewness of $.420(S E=.168)$. A highgrowth mindset was reported by $54 \%$ of participants, while $7 \%$ of participants reported a high fixed mindset. Low-growth mindset was reported by $7 \%$ of participants, while a low fixed mindset was reported by $75 \%$ (see Table 5).

A descriptive analysis in descending order of the specific items for levels of growth and fixed mindset was constructed with several noteworthy results. The growth and fixed mindset section of the scale asked students to rate their opinions about intelligence for a range of means from 1-7. Students responded positively to growth mindset item \#3: "No matter who you are, you can significantly change your intelligence level" $($ mean $=5.01 ; S D=1.21)$. The item that yielded the lowest mean response was \#8 "You can change even your basic intelligence level considerably" (mean $=4.64 ; S D=$ 1.29) (see Table 6). 
Table 5

Levels of Types of Mindset $(N=210)$

\begin{tabular}{lcr}
\hline Variable & Frequency & Percent \\
\hline Growth Mindset & & \\
Low & 13 & 6.0 \\
Medium & 83 & 40.0 \\
High & 114 & 54.0 \\
Total & 210 & 100.0 \\
& & \\
Fixed Mindset & & \\
Low & 158 & 75.0 \\
Medium & 37 & 18.0 \\
High & 15 & 7.0 \\
Total & 210 & 100.0 \\
\hline
\end{tabular}

Note. Low (mean range $=1.0-3.99)$, Medium (mean range $=4.0-$ 4.99), High (mean range $=5.0-7.0$ )

Table 6

Descending Descriptive Statistics of Growth Mindset $(N=210)$

\begin{tabular}{|c|c|c|c|c|c|}
\hline No. & Item & Mean & $S D$ & Min & Max \\
\hline$\# 3$ & $\begin{array}{l}\text { No matter who you are, you can } \\
\text { significantly change your } \\
\text { intelligence level. }\end{array}$ & 5.01 & 1.21 & 1.00 & 7.00 \\
\hline$\# 7$ & $\begin{array}{l}\text { No matter how much intelligence } \\
\text { you have, you can always change it } \\
\text { quite a bit. }\end{array}$ & 4.80 & 1.15 & 1.00 & 7.00 \\
\hline \#5 & $\begin{array}{l}\text { You can always substantially } \\
\text { change how intelligent you are. }\end{array}$ & 4.74 & 1.30 & 1.00 & 7.00 \\
\hline \#8 & $\begin{array}{l}\text { You can change even your basic } \\
\text { intelligence level considerably. }\end{array}$ & 4.64 & 1.29 & 1.00 & 7.00 \\
\hline
\end{tabular}

The fixed mindset yielded a lower mean response with \#6: "You can learn new things. But you can't really change your basic intelligence" $($ mean $=3.72 ; S D=1.54)$. Item \#2, "Your intelligence is something that you can't change very much" (mean = 2.88; $S D=1.36)$, resulted in the lowest mean response (see Table 7). 
Table 7

Descending Descriptive Statistics of Fixed Mindset $(N=210)$

\begin{tabular}{llllll}
\hline No. & Item & Mean & $S D$ & Min & Max \\
\hline$\# 6$ & $\begin{array}{l}\text { You can learn new things. But } \\
\text { you can't really change your basic } \\
\text { intelligence. }\end{array}$ & 3.72 & 1.54 & 1.00 & 7.00 \\
$\begin{array}{l}\text { You have a certain amount of } \\
\text { intelligence, and you can't really } \\
\text { do much about it. }\end{array}$ & 3.13 & 1.48 & 1.00 & 7.00 \\
$\begin{array}{l}\text { To be honest, you can't really } \\
\text { change how intelligent you are. } \\
\text { Your intelligence is something } \\
\text { about which you can't change } \\
\text { very much. }\end{array}$ & 2.93 & 1.34 & 1.00 & 7.00 \\
& & 1.36 & 1.00 & 7.00 \\
\end{tabular}

\section{Academic Motivation}

Intrinsic motivation was reported to be high $($ mean $=5.22 ; S D=.90)$ with a skewness of $+/-1(S E=.168)$ (see Table 4$)$. The participants also reported high levels of extrinsic motivation with a mean of $5.90(S D=.69)$ and a skewness of $+/-1(S E=.168)$. Amotivation was reported with a mean of $1.62(S D=.85)$ and a skewness $>$ than $+/-(S E$ $=.168)($ see Table 4).

High intrinsic motivation was reported by $64 \%$ of participants, while $10 \%$ reported low intrinsic motivation. High extrinsic motivation was reported by $89 \%$ of participants, while $1 \%$ of participants reported low extrinsic motivation. Amotivation was reported to be low by $96 \%$ of participants; $0 \%$ of respondents reported high amotivation (see Table 8).

A descriptive analysis in descending order of the specific items for intrinsic motivation, extrinsic motivation, and amotivation was constructed with several noteworthy results. The motivation section of the scale asked students to rate why they 
Table 8

Levels of Types of Academic Motivation $(N=210)$

\begin{tabular}{lrr}
\hline Variable & Frequency & Percent \\
\hline Intrinsic Motivation & & \\
Low & 20 & 10.0 \\
Medium & 54 & 25.7 \\
High & 136 & 64.7 \\
Total & 210 & 100.0 \\
Extrinsic Motivation & & \\
Low & 2 & 1.0 \\
Medium & 21 & 10.0 \\
High & 187 & 89.0 \\
Total & 210 & 100.0 \\
& & \\
Amotivation & & 96.0 \\
Low & 202 & 4.0 \\
Medium & 8 & 0.0 \\
High & 0 & 100.0 \\
Total & 210 & \\
\hline
\end{tabular}

Note. Low (mean range $=1.0-3.99)$, Medium (mean range $=4.0-$ 4.99), High (mean range $=5.0-7.0)$

went to college. Students responded positively to intrinsic motivation item \#23:

"Because my studies allow me to continue to learn about many things that interest me" $($ mean $=6.01 ; S D=1.05)$. Also highly scored was item \#16: "For the pleasure that I experience in broadening my knowledge about subject which appeals to me" (mean = 5.90; $S D=1.08)$. Participants responded positively to item \#2: "Because I experience pleasure and satisfaction while learning new things" (mean $=5.86 ; S D=.99)$. The responses with the lowest means were item \#11: "For the pleasure that I experience when I read interesting authors" (mean $=4.39 ; S D=1.53$ ) and item \#18: "For the pleasure that I experience when I feel completely absorbed by what certain authors have written" (mean $=4.22 ; S D=1.54)($ see Table 9$)$. 
Table 9

Descending Descriptive Statistics of Intrinsic Motivation $(N=210)$

\begin{tabular}{|c|c|c|c|c|c|}
\hline No. & Item & Mean & $S D$ & Min & Max \\
\hline$\# 23$ & $\begin{array}{l}\text { Because my studies allow me to } \\
\text { continue to learn about many } \\
\text { things that interest me. }\end{array}$ & 6.01 & 1.05 & 1.00 & 7.00 \\
\hline \#16 & $\begin{array}{l}\text { For the pleasure that I experience } \\
\text { in broadening my knowledge about } \\
\text { subject which appeal to me. }\end{array}$ & 5.90 & 1.08 & 2.00 & 7.00 \\
\hline \#2 & $\begin{array}{l}\text { Because I experience pleasure and } \\
\text { satisfaction while learning new } \\
\text { things. }\end{array}$ & 5.86 & .99 & 3.00 & 7.00 \\
\hline \#9 & $\begin{array}{l}\text { For the pleasure I experience when } \\
\text { I discover new things never seen } \\
\text { before. }\end{array}$ & 5.63 & 1.14 & 2.00 & 7.00 \\
\hline \#27 & $\begin{array}{l}\text { Because college (CEGEP) allows } \\
\text { me to experience a personal } \\
\text { satisfaction in my quest for } \\
\text { excellence in my studies. }\end{array}$ & 5.61 & 1.19 & 1.00 & 7.00 \\
\hline \#13 & $\begin{array}{l}\text { For the pleasure that I experience } \\
\text { while I am surpassing myself in } \\
\text { one of my personal } \\
\text { accomplishments. }\end{array}$ & 5.53 & 1.21 & 1.00 & 7.00 \\
\hline \#20 & $\begin{array}{l}\text { For the satisfaction I feel when I } \\
\text { am in the process of accomplishing } \\
\text { difficult academic activities. }\end{array}$ & 5.48 & 1.28 & 1.00 & 7.00 \\
\hline \#6 & $\begin{array}{l}\text { For the pleasure I experience } \\
\text { while surpassing myself in my } \\
\text { studies. }\end{array}$ & 5.08 & 1.24 & 1.00 & 7.00 \\
\hline \#4 & $\begin{array}{l}\text { For the intense feelings I } \\
\text { experience when I am } \\
\text { communicating my own ideas to } \\
\text { others. }\end{array}$ & 4.56 & 1.39 & 2.00 & 7.00 \\
\hline$\# 25$ & $\begin{array}{l}\text { For the "high" feeling that I } \\
\text { experience while reading about } \\
\text { various interesting subjects. }\end{array}$ & 4.40 & 1.52 & 1.00 & 7.00 \\
\hline$\# 11$ & $\begin{array}{l}\text { For the pleasure that I experience } \\
\text { when I read interesting authors. }\end{array}$ & 4.39 & 1.53 & 1.00 & 7.00 \\
\hline$\# 18$ & $\begin{array}{l}\text { For the pleasure that I experience } \\
\text { when I feel completely absorbed } \\
\text { by what certain authors have } \\
\text { written. }\end{array}$ & 4.22 & 1.54 & 1.00 & 7.00 \\
\hline
\end{tabular}


Extrinsic motivation items of why students go to college indicated fairly high responses ranging from the highest with a mean score of 6.66 and the lowest with a mean of 5.32 on a scale of 1-7. Item \#3 that stated, "Because I think that college education will help me better prepare for the career I have chosen" (mean $=6.66$; $S D=.64)$, was the highest rated item of not only the extrinsic items presented, but of all items measuring independent variables presented for the entire scale. Also, highly scored is extrinsic motivation item \#10: "Because eventually it will enable me to enter the job market in a field that I like" (mean $=6.48 ; S D=.76)$ and \#24: "Because I believe that a few additional years of education will improve my competence as a worker" $($ mean $=6.02$; $S D=1.08)$. Extrinsic motivation items on the lower end of the scale were items \#1: "Because with only a high school diploma I would not find a high paying job later on" (mean $=5.48 ; \mathrm{SD}=1.49)$, \#14: "Because of the fact that when I succeed in college I feel important" (mean $=5.45 ; S D=1.33)$, and \#21 "To show myself that I am an intelligent person" $($ mean $=5.32 ; S D=1.39)($ see Table 10$)$.

Amotivation items indicated the lowest overall mean scores. Responses to amotivation item \#12, "I once had good reasons for going to college however, now I wonder whether I should continue" (mean $=1.83 ; S D=1.19)$, scored the highest in this section. Item \# 19 presents the lowest scored response of the motivation section with a mean of 1.45 and a $S D$ of .88 stating "I can't see why I go to college and frankly, I couldn't care less"' (see Table 11).

\section{Academic Self-Efficacy}

Academic self-efficacy was relatively high with a mean of $5.08(S D=.83)$ and a skewness of $+/-1(S E=.168)$ (see Table 2). Academic self-efficacy was reported as high 
Table 10

Descending Descriptive Statistics of Extrinsic Motivation $(N=210)$

\begin{tabular}{|c|c|c|c|c|c|}
\hline No. & Item & Mean & $S D$ & Min & Max \\
\hline$\# 3$ & $\begin{array}{l}\text { Because I think that a college } \\
\text { education will help me better } \\
\text { prepare for the career I have } \\
\text { chosen. }\end{array}$ & 6.66 & .64 & 4.00 & 7.00 \\
\hline \#10 & $\begin{array}{l}\text { Because eventually it will enable } \\
\text { me to enter the job market in a } \\
\text { field that I like. }\end{array}$ & 6.48 & .76 & 2.00 & 7.00 \\
\hline$\# 24$ & $\begin{array}{l}\text { Because I believe that a few } \\
\text { additional years of education will } \\
\text { improve my competence as a } \\
\text { worker. }\end{array}$ & 6.02 & 1.08 & 1.00 & 7.00 \\
\hline \#8 & $\begin{array}{l}\text { In order to obtain a more } \\
\text { prestigious job later on. }\end{array}$ & 5.97 & 1.16 & 2.00 & 7.00 \\
\hline \#22 & $\begin{array}{l}\text { In order to have a better salary later } \\
\text { on. }\end{array}$ & 5.96 & .97 & 2.00 & 7.00 \\
\hline \#17 & $\begin{array}{l}\text { Because this will help me make a } \\
\text { better choice regarding my career } \\
\text { orientation. }\end{array}$ & 5.95 & 1.05 & 2.00 & 7.00 \\
\hline \#28 & $\begin{array}{l}\text { Because I want to show myself that } \\
\text { I can succeed in my studies. }\end{array}$ & 5.84 & 1.11 & 3.00 & 7.00 \\
\hline$\# 15$ & $\begin{array}{l}\text { Because I want to have "the good } \\
\text { life" later on. }\end{array}$ & 5.74 & 1.15 & 2.00 & 7.00 \\
\hline \#7 & $\begin{array}{l}\text { To prove myself that I am capable } \\
\text { of completing my college degree. }\end{array}$ & 5.60 & 1.29 & 1.00 & 7.00 \\
\hline \#1 & $\begin{array}{l}\text { Because with only a high-school } \\
\text { degree I would not find a high- } \\
\text { paying job later on. }\end{array}$ & 5.48 & 1.49 & 1.00 & 7.00 \\
\hline$\# 14$ & $\begin{array}{l}\text { Because of the fact that when I } \\
\text { succeed in college I feel important. }\end{array}$ & 5.45 & 1.33 & 1.00 & 7.00 \\
\hline$\# 21$ & $\begin{array}{l}\text { To show myself that I am an } \\
\text { intelligent person. }\end{array}$ & 5.32 & 1.39 & 1.00 & 7.00 \\
\hline
\end{tabular}


Table 11

Descending Descriptive Statistics of Amotivation $(N=210)$

\begin{tabular}{|c|c|c|c|c|c|}
\hline No. & Item & Mean & $S D$ & Min & $\operatorname{Max}$ \\
\hline$\# 12$ & $\begin{array}{l}\text { I once had good reasons for } \\
\text { going to college; however, now } \\
\text { I wonder whether I should } \\
\text { continue. }\end{array}$ & 1.83 & 1.19 & 1.00 & 7.00 \\
\hline$\# 5$ & $\begin{array}{l}\text { Honestly, I don't know; I really } \\
\text { feel that I am wasting my time } \\
\text { in school. }\end{array}$ & 1.71 & .98 & 1.00 & 5.00 \\
\hline \#26 & $\begin{array}{l}\text { I don't know; I can't understand } \\
\text { what I am doing in school. }\end{array}$ & 1.49 & .87 & 1.00 & 5.00 \\
\hline \#19 & $\begin{array}{l}\text { I can't see why I go to college } \\
\text { and frankly, I couldn't care less. }\end{array}$ & 1.45 & .88 & 1.00 & 7.00 \\
\hline
\end{tabular}

by $54 \%$ of participants, while $34 \%$ reported medium levels. Finally, $12 \%$ of participants reported low academic self-efficacy (see Table 12).

A descriptive analysis in descending order of the specific items for levels of academic self-efficacy was constructed with several noteworthy results. The academic self-efficacy section of the scale asking students to rate their opinions about their ability to succeed academically ranged from 1 to 7 . Students responded positively to item \#7

Table 12

Levels of Academic Self-Efficacy

\begin{tabular}{lcc}
\hline Level of Academic self-efficacy & Frequency & Percent \\
\hline Low & 24 & 12.0 \\
Medium & 72 & 34.0 \\
High & 114 & 54.0 \\
Total & 210 & 100.0 \\
\hline
\end{tabular}

Note. Low (mean range $=1.0-3.99)$, Medium (mean range $=4.0-4.99$ ), High (mean range $=5.0-7.0$ ) 
"Attending class regularly" (means $=6.35 ; S D=.942$ ), item \#23 "Using a computer" (mean $=6.08 ; S D=.987)$, and item \#18 "Attending class consistently in a dull course" $($ mean $=6.08 ; \mathrm{SD}=1.25)$. Academic self-efficacy item \#3 "Answering a question in a large room" (mean = 4.00; $S D=1.73)$, \#14 "Running for student office government office" (mean $=3.30 ; S D=1.75$ ), and \#27 "Challenging a professor's opinion in class" (mean $=2.99 ; S D=1.65)$ indicated the lowest mean responses from participants (see Table 13).

Overall, a majority of undergraduate communication sciences and disorders students reported higher than average GPAs with 29.5\% reporting a GPA ranging from 3.1 to 3.59 and $63.3 \%$ reporting a GPA range of 3.6 to 4.0 (see Table 3). Undergraduate communication sciences and disorders students also noted high extrinsic motivation $($ mean $=5.90 ; \mathrm{SD} .69)$, intrinsic motivation $($ mean $=5.22 ; \mathrm{SD}=.90)$, and low amotivation $($ mean $=1.62 ; \mathrm{SD}=.85)($ see Table 3$)$. Several of the items measuring extrinsic motivation were highly rated. Item \#3 had a mean score of 6.66 , noting that students go to college "Because I think that a college education will help me better prepare for the career I have chosen." Item 10 had a mean score of 6.48 (student goes to college because it will enable "me" to enter the job market in a field that "I" like). Ninety-six percent of the sample fell within the range of low levels of amotivation, further indicating that more undergraduate communication sciences and disorders students are more motivated by external factors than internal factors, or by no motivation at all. 
Table 13

Descending Descriptive Statistics of Academic Self-Efficacy $(N=210)$

\begin{tabular}{|c|c|c|c|c|c|}
\hline No. & Item & Mean & $S D$ & Min & Max \\
\hline \#7 & Attending Class Regularly & 6.35 & .94 & 2.00 & 7.00 \\
\hline \#23 & Using a Computer & 6.08 & .99 & 3.00 & 7.00 \\
\hline \#18 & $\begin{array}{l}\text { Attending class Consistently in } \\
\text { a dull course }\end{array}$ & 6.08 & 1.25 & 1.00 & 7.00 \\
\hline \#30 & Getting good grades & 5.88 & 1.04 & 3.00 & 7.00 \\
\hline$\# 12$ & $\begin{array}{l}\text { Earning good marks in a most } \\
\text { courses }\end{array}$ & 5.73 & 1.21 & 2.00 & 7.00 \\
\hline \#21 & $\begin{array}{l}\text { Understanding most ideas } \\
\text { presented in class }\end{array}$ & 5.69 & .99 & 3.00 & 7.00 \\
\hline \#19 & $\begin{array}{l}\text { Making a professor think } \\
\text { you're paying attention }\end{array}$ & 5.63 & 1.22 & 1.00 & 7.00 \\
\hline$\# 26$ & $\begin{array}{l}\text { Relating course content to } \\
\text { materials in other classes }\end{array}$ & 5.58 & 1.16 & 2.00 & 7.00 \\
\hline$\# 22$ & $\begin{array}{l}\text { Performing simple math } \\
\text { computation }\end{array}$ & 5.48 & 1.41 & 2.00 & 7.00 \\
\hline \#13 & $\begin{array}{l}\text { Studying enough to understand } \\
\text { content thoroughly }\end{array}$ & 5.47 & 1.20 & 2.00 & 7.00 \\
\hline \#5 & Taking multiple choice tests & 5.45 & 1.36 & 1.00 & 7.00 \\
\hline$\# 1$ & Taking well-organized notes & 5.43 & 1.41 & 1.00 & 7.00 \\
\hline$\# 16$ & Making professors respect you & 5.35 & 1.35 & 1.00 & 7.00 \\
\hline$\# 15$ & $\begin{array}{l}\text { Participating in extra-curricular } \\
\text { events (sports, clubs) }\end{array}$ & 5.26 & 1.62 & 1.00 & 7.00 \\
\hline$\# 20$ & $\begin{array}{l}\text { Understanding most ideas you } \\
\text { read in your texts. }\end{array}$ & 5.20 & 1.21 & 1.00 & 7.00 \\
\hline \#4 & $\begin{array}{l}\text { Answering a question in a } \\
\text { small class }\end{array}$ & 5.18 & 1.50 & 1.00 & 7.00 \\
\hline$\# 10$ & $\begin{array}{l}\text { Explaining a concept to } \\
\text { another student }\end{array}$ & 5.13 & 1.24 & 1.00 & 7.00 \\
\hline \#8 & $\begin{array}{l}\text { Listening carefully during a } \\
\text { lecture on a difficult topic }\end{array}$ & 5.11 & 1.38 & 1.00 & 7.00 \\
\hline \#28 & $\begin{array}{l}\text { Applying lecture content to a } \\
\text { laboratory session }\end{array}$ & 4.92 & 1.33 & 1.00 & 7.00 \\
\hline$\# 24$ & $\begin{array}{l}\text { Mastering most content in a } \\
\text { math course }\end{array}$ & 4.91 & 1.65 & 1.00 & 7.00 \\
\hline \#6 & Taking essay tests & 4.87 & 1.43 & 2.00 & 7.00 \\
\hline$\# 25$ & $\begin{array}{l}\text { Talking to a professor privately } \\
\text { to get to know him or her }\end{array}$ & 4.86 & 1.59 & 1.00 & 7.00 \\
\hline \#7 & $\begin{array}{l}\text { Writing a high-quality term } \\
\text { paper }\end{array}$ & 4.85 & 1.52 & 1.00 & 7.00 \\
\hline \#33 & $\begin{array}{l}\text { Mastering content in a course } \\
\text { you're not interested in }\end{array}$ & 4.83 & 1.33 & 1.00 & 7.00 \\
\hline
\end{tabular}


Table 13-Continued.

\begin{tabular}{|c|c|c|c|c|c|}
\hline No. & Item & Mean & $S D$ & Min & Max \\
\hline \#29 & Making good use of the library & 4.83 & 1.68 & 1.00 & 7.00 \\
\hline \#9 & Tutoring another student & 4.68 & 1.47 & 1.00 & 7.00 \\
\hline \#31 & $\begin{array}{l}\text { Spreading out studying instead } \\
\text { of cramming }\end{array}$ & 4.67 & 1.60 & 1.00 & 7.00 \\
\hline \#11 & $\begin{array}{l}\text { Asking a professor in class to } \\
\text { review a concept you don't } \\
\text { understand }\end{array}$ & 4.65 & 1.66 & 1.00 & 7.00 \\
\hline \#2 & $\begin{array}{l}\text { Participating in a class } \\
\text { discussion }\end{array}$ & 4.65 & 1.64 & 1.00 & 7.00 \\
\hline \#32 & $\begin{array}{l}\text { Understanding difficult } \\
\text { passages in textbooks }\end{array}$ & 4.60 & 1.36 & 1.00 & 7.00 \\
\hline \#3 & $\begin{array}{l}\text { Answering a question in a } \\
\text { large class }\end{array}$ & 4.00 & 1.73 & 1.00 & 7.00 \\
\hline \#14 & $\begin{array}{l}\text { Running for student } \\
\text { government office }\end{array}$ & 3.30 & 1.75 & 1.00 & 7.00 \\
\hline \#27 & $\begin{array}{l}\text { Challenging a professor's } \\
\text { opinion in class }\end{array}$ & 2.99 & 1.65 & 1.00 & 7.00 \\
\hline
\end{tabular}

Growth mindset $($ mean $=4.80 ; S D=1.07)$ was reported to be higher than fixed mindset (mean $=3.16 ; S D=1.23$ ), with $54 \%$ reporting high levels of growth mindset and 7\% reporting high levels of fixed mindset (see Table 3 , Table 4). Item \# 3 of the mindset section (No matter who you are, you can significantly change your intelligence level) of growth mindset measures was high with a mean of $5.01(S D=1.21)$.

Self-efficacy was reported to be fairly high with a mean of $5.08(S D=.83)$ with $54 \%$ scoring in the high range for self-efficacy and $34 \%$ scoring in the medium range.

\section{Research Question 2}

To what extent are mindset, academic motivation, and academic self-efficacy, related to the academic achievement of students pursuing an undergraduate degree in the 
field of communication sciences and disorders at selected Great Lakes States universities?

To investigate the influence and levels of statistical dependence of academic achievement, mindset, academic motivation, and academic self-efficacy, a Spearman rank correlation model was conducted. The Spearman rank correlation model was used because the data being analyzed was ordinal in nature. Spearman rank measures the strength of the monotonic relationships between paired data.

The correlation, which is an effect size, can be described through a narrative depiction of the $r_{s}$ ranging from "very weak" to "very strong" (Spearman's Correlation, n.d.).

A strong negative monotonic correlation was found for growth mindset and fixed mindset of undergraduate communication sciences and disorders students, $r_{s}=-.719, p$ $($ two-tailed $)<.001($ see Table 14$)$, therefore indicating that as growth mindset $($ mean $=$ 4.80) increases, fixed mindset $($ mean $=3.16)$ decreases (see Table 14).

A moderate positive monotonic correlation was found for intrinsic motivation and extrinsic motivation of undergraduate communication sciences and disorders students, $r_{s}$ $=.518, p$ (two-tailed) $<.001$. This shows a monotonical function that never decreases, noting that as intrinsic motivation $($ mean $=5.22)$ increases, extrinsic motivation $($ mean $=$ 5.90) never decreases, indicating a weak negative monotonic correlation of intrinsic motivation and amotivtion of the sample population, $r_{s}=.-379, p$ (two-tailed) $<.001$. This indicates that higher intrinsic motivation $($ mean $=5.22)$ scores are associated with lower amotivation scores $($ mean $=1.62)$. Intrinsic motivation was also found to have a moderate positive monotonic correlation to academic self-efficacy $\left[r_{s}=.447, p\right.$ (two- 
Table 14

Spearman Rank Correlation of GPA, Mindset, Academic Motivation, and Academic Self-Efficacy

\begin{tabular}{|c|c|c|c|c|c|c|}
\hline Variable & 2 & 3 & 4 & 5 & 6 & 7 \\
\hline 1 Growth Mindset & $-.719 * *$ & .132 & .090 & -.016 & .059 & $-.144 *$ \\
\hline 2 Fixed Mindset & & -.049 & -.011 & .118 & -.068 & .069 \\
\hline $\begin{array}{l}3 \text { Intrinsic } \\
\text { Motivation }\end{array}$ & & & $.518 * *$ & $-.379 * *$ & $.447 * *$ & -.011 \\
\hline $\begin{array}{l}4 \text { Extrinsic } \\
\text { Motivation }\end{array}$ & & & & $-.323 * *$ & $.310 * *$ & -.028 \\
\hline 5 Amotivation & & & & & $-.352 * *$ & $-.292 * *$ \\
\hline $\begin{array}{l}6 \text { Academic Self- } \\
\text { efficacy }\end{array}$ & & & & & & $.195 * *$ \\
\hline 7 What is your GPA? & & & & & & \\
\hline
\end{tabular}

tailed $<.001$ ], indicating that higher academic self-efficacy scores are associated with higher intrinsic motivation.

Extrinsic motivation and amotivation were found to have a weak negative monotonical correlation $r_{s}=-.323, p$ (two-tailed) $<.001$. Extrinsic motivation, however, has a weak positive monotonic correlation to academic self-efficacy, $r_{s}=.310, p$ (twotailed $<.001$. Amotivation and academic self-efficacy were found to indicate a weak negative monotonic correlation, $\left[r_{s}=-.352, p\right.$ (two-tailed) $\left.<.001\right]$ (see Table 14).

The dependent variable GPA was found to have a very weak negative monotonical correlation with growth mindset $\left[r_{s}=-.144, p(\right.$ two-tailed $\left.)=.037\right]$. Grade point average has a weak positive monotonical correlation with academic self-efficacy $\left[r_{s}=.195, p(\right.$ two-tailed $\left.)=.005\right]$ and a weak negative monotonical correlation with amotivation $\left[r_{s}=-.292, p(\right.$ two-tailed $\left.)<.001\right]$ (see Table 14). 
Because the dependent variable was categorical in nature, a CATREG was utilized. According to IBM Knowledge Center, "Categorical regression quantifies categorical data by assigning numerical values to the categories, resulting in an optimal linear regression equation for the transformed variables" (CATREG, 2012, para. 1). The CATREG was run utilizing 210 cases. Several CATREG equations were conducted. The initial equation included the independent variables of fixed and growth mindset; next, intrinsic, extrinsic, and amotivation were added in the second analysis; and finally, the last equation included the five variables noted above with the addition of selfefficacy.

The first CATREG included fixed and growth mindsets as the independent variables and GPA as the dependent variable. The equation reported was not significant $[\mathrm{F}(2,207)=$ $2.11 ; p=.124]$ with an $R^{2}$ of .020 and an adjusted $R^{2} .010$ (see Table 15). This would explain a $2 \%$ variance between growth mindset, fixed mindset, and GPA. The Pratt's Measure of Relative Importance indicated that growth mindset had a level of Importance at 1.08. Further, fixed mindset indicated an Importance at -.077 which also denotes no contributing variance to GPA.

Table 15

Correlations, Coefficients, $p$ Values, and Importance of Mindset (Fixed Mindset, Growth Mindset) to GPA (CATREG)

\begin{tabular}{llllll}
\hline Variable & Standardized & \multicolumn{4}{c}{ Correlations } \\
\cline { 3 - 5 } & Coefficient-Beta & Zero-Order & Partial & Part & Importance \\
\hline Growth & -.153 & -.141 & -.106 & -.105 & 1.08 \\
Mindset & & & & \\
Fixed Mindset & -.016 & .095 & -.011 & -.011 & -.077 \\
\hline $\begin{array}{l}\text { Note. Dependent Variable: GPA; Multiple } R=.141 ; R^{2}=.020 ; \\
d f(2,207) ; F=2.11 ; \text { Sig }=.124\end{array}$ & & &
\end{tabular}


The second CATREG equation computed included the independent variables of fixed mindset, growth mindset, intrinsic motivation, extrinsic motivation, and amotivation. A significant regression equation was found $[F(5,204)=7.90 ; \mathrm{p}<.001]$ with an $R^{2}$ of .162 and an adjusted $R^{2}$ of .142 . The six independent variables included in this equation account for $16.2 \%$ of the variance of the achievement (GPA) in undergraduate communication sciences and disorders students (see Table 16).

Pratt's Measure of Relative Importance indicated that growth mindset had an Importance of .035 and fixed mindset had an importance of .054. Intrinsic motivation revealed the least amount of importance within this equation of .002. Extrinsic motivation had an importance of .044 , while amotivation indicated the greatest level of importance at .866 , therefore, noting that within the equation, amotivation is most likely

Table 16

Correlations, Coefficients, $p$ Values and Importance of Mindsets (Fixed Mindset, Growth Mindset) and Motivation (Intrinsic, Extrinsic, and Amotivation) to GPA (CATREG)

\begin{tabular}{|c|c|c|c|c|c|}
\hline \multirow[t]{2}{*}{ Variable } & \multirow{2}{*}{$\begin{array}{l}\text { Standardized } \\
\text { Coefficient-Beta }\end{array}$} & \multicolumn{4}{|c|}{ Correlations } \\
\hline & & Zero-Order & Partial & Part & Importance \\
\hline $\begin{array}{l}\text { Growth } \\
\text { Mindset }\end{array}$ & -.042 & -.134 & -.030 & -.027 & .035 \\
\hline $\begin{array}{l}\text { Fixed } \\
\text { Mindset }\end{array}$ & .115 & .076 & -.082 & -.075 & .054 \\
\hline $\begin{array}{l}\text { Intrinsic } \\
\text { Motivation }\end{array}$ & -.086 & -.004 & -.077 & -.071 & .002 \\
\hline $\begin{array}{l}\text { Extrinsic } \\
\text { Motivation }\end{array}$ & -.130 & -.054 & -.121 & -.112 & .044 \\
\hline Amotivation* & -.422 & -.333 & -.378 & -.374 & .866 \\
\hline
\end{tabular}


responsible for the increased level of significance (see Table 16). These findings resulted in the need to conduct a third equation.

The third CATREG equation was calculated incorporating the variables, growth mindset, fixed mindset, intrinsic motivation, extrinsic motivation, amotivation, and selfefficacy. This revealed a significant regression equation with $[F(2,206)=7.61 ; p<.001]$ with an $R^{2}$ of .184 and an adjusted $R^{2}$ of .160 . This equation indicated that $18.4 \%$ of student achievement can be explained by growth mindset, fixed mindset, intrinsic motivation, extrinsic motivation, amotivation, and self-efficacy (see Table 17).

The Pratt's Measure of Relative Importance indicated that growth mindset (Importance $=.024)$ and intrinsic motivation have the least levels of importance to academic achievement, while amotivation (Importance $=.690)$ and academic selfefficacy (Importance $=.182$ ) have the greatest levels of importance to academic achievement (GPA).

Categorical regression analyses were executed for the dependent variable GPA and the following independent variables: growth mindset, fixed mindset, intrinsic motivation, extrinsic motivation, and academic self-efficacy. A significant model including growth mindset, fixed mindset, intrinsic motivation, extrinsic motivation, and amotivation was reported $[F(5,204)=7.90 ; p<.000]$ with an $R^{2}$ of .162 and an adjusted $R^{2}$ of .142 (see Table 16$)$. Within this model, amotivation (Importance $=.866$ ) was the only independent variable of significance. This negative significance explained $16 \%$ of the variance of GPA in undergraduate communication sciences and disorders students. Table 17 included the independent variables growth mindset, fixed mindset, intrinsic motivation, extrinsic motivation, and academic self-efficacy, $\left[F_{(6,203)}=.184 ; p<.000\right]$ 
Table 17

Correlations, Coefficients, $p$ Values and Importance of Mindsets (Fixed Mindset, Growth Mindset), Motivation (Intrinsic, Extrinsic, and Amotivation) and Self-Efficacy to GPA (CATREG)

\begin{tabular}{|c|c|c|c|c|c|}
\hline \multirow[t]{2}{*}{ Variable } & \multirow{2}{*}{$\begin{array}{l}\text { Standardized } \\
\text { Coefficient-Beta }\end{array}$} & \multicolumn{4}{|c|}{ Correlations } \\
\hline & & Zero-Order & Partial & Part & Importance \\
\hline $\begin{array}{l}\text { Growth } \\
\text { Mindset }\end{array}$ & -.032 & -.137 & -.024 & -.021 & .024 \\
\hline $\begin{array}{l}\text { Fixed } \\
\text { Mindset }\end{array}$ & .125 & .082 & -.091 & -.082 & .056 \\
\hline $\begin{array}{l}\text { Intrinsic } \\
\text { Motivation }\end{array}$ & -.141 & -.003 & -.121 & -.110 & .002 \\
\hline $\begin{array}{l}\text { Extrinsic } \\
\text { Motivation }\end{array}$ & -.140 & -.059 & -.132 & -.120 & .045 \\
\hline Amotivation* & -.386 & -.329 & -.348 & -.336 & .690 \\
\hline $\begin{array}{l}\text { Academic } \\
\text { Self-Efficacy* }\end{array}$ & .169 & .198 & .163 & .149 & .182 \\
\hline
\end{tabular}

Note. Dependent Variable: GPA; Multiple $R=.429 ; R^{2}=.184$; Adjusted $R^{2}=.160$; $d f(6,203) ; F=7.61 ; \operatorname{Sig}=.000$

*Variable with significant correlation

with an $R^{2}$ of .184 and an adjusted $R^{2}$ of .160 . Pratt's Measures of Relative Importance indicated that amotivation $($ Importance $=.690)$ and academic self-efficacy $($ Importance $=$ .182) contributed the most to the variance of GPA. Therefore, $18.4 \%$ of variance of GPA can be explained through amotivation and academic self-efficacy. Hence, the higher the GPA, the lower the amotivation, and the higher the academic self-efficacy. Growth mindset, fixed mindset, intrinsic motivation, and extrinsic motivation were not found to be related to GPA.

\section{Summary of Major Findings}

The sample population reported average to higher than average GPAs with $93 \%$ of respondents reporting GPAs between 3.1 and 4.0. The respondents reported high 
means in the area of extrinsic motivation with $89 \%$ reporting mean scores of .50 to 7.0 and significantly low scores in amotivation with $96 \%$ reporting mean scores of 1.0 to 3.99.

Intrinsic motivation (64.7\% reported mean scores of 5.0 to7.0) and academic selfefficacy (54\% reported mean score of 5.0 to 7.0 ) scores, while lower than extrinsic motivation, were also moderately high. The results of this study also indicated no significant relationship between GPA and growth mindset, fixed mindset, intrinsic motivation, and extrinsic motivation. A significant negative relationship however, was found between amotivation scores and GPA, indicating that individuals in this current study with high GPA reported low amotivation. A significant relationship was also found between academic self-efficacy and GPA, indicating that participants in the study with high GPAs also reported high academic self-efficacy. 


\section{CHAPTER 5}

\section{SUMMARY, DISCUSSION, AND IMPLICATIONS}

\section{Introduction}

This chapter summarizes the details of the previous four chapters by reviewing the purpose of the study, providing a synoptic review of the literature, the methodological procedures utilized, and the critical outcomes of the study. The implications, limitations, and recommendations for future study, are also considered.

\section{Purpose of the Study}

Student achievement is often affected by mindset (Dweck, 2006), academic motivation (Deci \& Ryan, 1985), and academic self-efficacy (Bandura, 1977). The purpose of this study was to determine the extent to which types of mindset, types of academic motivation, and types of academic self-efficacy were correlated with academic achievement among students pursuing an undergraduate degree in the field of communication sciences and disorders at selected Great Lakes States institutions.

\section{Summary of Literature}

Academic achievement is the ultimate desired outcome of education. It is also tangible product and proof that a student has engaged in active learning (Ward et al., 1996). The historical path of academic achievement can be traced to before the nineteenth century when students were taught in a one-on-one mentorship model 
(Hartmann, 2012). However, in the nineteenth century, as a means of being able to engage more students, scholars and teachers from institutions such as Yale College, the College of William and Mary, and Harvard University began using a grading system to judge achievement (Durm, 1993; Gehrz, 2012).

Wahlberg (1984) explained student achievement through the lens of his educational productivity theory (EPT), which emphasized that for students to achieve academic success, there must be a balance of student ability, age, motivation, time spent on tasks and engaged in learning, quality of instruction, home environment, school environment, peer group choices, and quality of time spent out of school. McGrew (2008), in his Model of Academic Competence and Motivation (MACM), stressed that the first three factors of the EPT (ability, age of development, and motivation), reflect the characteristics of the student (McGrew, 2008).

Mindset refers to the two opposing frameworks that classify people by the way they see and understand intelligence. Fixed mindset is described as an individual's belief that someone is born with a certain amount of intelligence that cannot grow or change. Growth mindset, however, is described as a belief that one's intelligence is malleable (Dweck \& Leggett, 1988). The mindset theory was constructed through an amalgamation of Kelly's theory of personality and Heider's theory of social perception. The theorists postulated that naïve assumptions and latent beliefs influence people's conclusions and perceptions about themselves and others (Dweck et al., 1995; Heider, 1958; Kelly, 1955).

Dweck and Leggett (1988) found that subjects who had a growth mindset were more resilient, worked harder to complete tasks, and engaged in more attempts to solve problems. Those who were identified as having a fixed mindset became frustrated and 
often gave up before trying. Individuals can experience different types of mindset based on various content areas. Some can present with a fixed mindset and goal orientation for math skills, and a growth mindset and goal orientation for English, science, or language arts. The presumed malleability of the mindset construct may be responsible for this variability (Leonardi \& Gialamas, 2002).

Gondida et al.'s (2006) findings contradict those of Dweck and Leggett (1988) in that they found no significant link between academic achievement and mindset. The results of their study revealed that mindset was actually mediated by self-efficacy and prior achievements.

Magno (2012) found that students with a growth mindset tended to adopt a mastery approach to goal orientation, while those with a fixed mindset tended to adopt performance avoidance approaches. However, student achievement goal orientation did not significantly predict GPA. Mindset tended to be rather stable by the time students reached the college level, and it correlated significantly with levels of self-esteem (Robins \& Pals, 2002).

Theorists and scientists such as Freud, Maslow, and Descartes believed that motivation was as simple as a desire between life and death, a need for nourishment, and the passive and active differences between the body and the will (Pakdel, 2013; Qadeer, 2009). These viewpoints have had a strong influence on the evolution and development of theories such as the self-determination theory by Deci and Ryan (1985), which postulated that there is a natural tendency toward development and growth.

Separated into three constructs of intrinsic motivation, extrinsic motivation, and amotivation, academic motivation is concerned with the personality traits that drive 
people's choices and inherent self-motivation (Ryan \& Deci, 2000; Vallerand et al., 1992). Vallerand et al. (1992) described intrinsic motivation as being experienced by one who engages in an activity for the gratification and fulfillment it brings. Extrinsic motivation was described as a form of motivation in which activities are engaged in as "means to an end and not for their own sake" (Deci, 1975, p. 23). Amotivation was described as a lack of motivation when one is neither intrinsically nor extrinsically motivated. Individuals who are amotivated are often plagued by feelings of inadequacy and inability (Vallerand et al., 1992).

Undergraduate, high school, and elementary students demonstrate lower levels of intrinsic motivation than graduate students (Hegarty, 2010). Graduate students appeared to exhibit more performance-based motivation than mastery-based motivation which may lead one to assume that as education advances, one may become more extrinsically motivated. Undergraduate students in the United States have greater levels of extrinsic motivation than their peers in Turkey (Isiksal, 2010). However, this extrinsic motivation declined as they progressed through the years of undergraduate school, contradicting Hegarty's (2010) findings.

While type and level of motivation can vary based on levels of academic completion, there may be little difference between academic major and area of interest (Durso et al., 2016). However, differences have been found with levels of motivation and academic self-efficacy based on race. Long et al. (2016) found that African-American students demonstrated lower levels of motivational variables and achievement in comparison to their White peers, while (Cokely (2003) found that scores for these 
students on extrinsic motivation, intrinsic motivation, and underachievement were conflicting.

Self-efficacy is defined as "a person's belief in his or her ability to succeed in specific situations" (Strive together, 2013, p. 3). Lennon (2010) noted that self-efficacy was “a cognitive assessment of one's ability” (p. 93). According to Bandura (1977), levels of self-efficacy may affect performance, persistence, and even academic motivation. Like mindset and academic motivation, self-efficacy is malleable and can be strengthened or weakened (Bandura, 1977, Dweck, 2010; Mehrabi et al., 2016). High levels of academic self-efficacy are present when students look at failure as a lack of effort, rather than a lack of shortcomings (Bandura, 1977).

There was a strong link between academic self-efficacy and academic expectations (Chemers et al., 2001; Kahn, 2013). Levels of high school academic selfefficacy predicted academic self-efficacy at the college level. Therefore, students entering college with high levels of academic self-efficacy were predicted to perform significantly better than those with lower levels in high school (Chemers et al., 2001). While students in college often worry, researchers found no significant relationship between levels of self-efficacy, worry, and academic achievement. While the assessment of the frequency of worry rather than the level may have been more appropriate, the study denotes that worry does affect levels of self-efficacy and achievement (Tang \& Westwood, 2007).

Ozer \& Akgun (2015) confirmed that there is a positive relationship between irrational beliefs, academic motivation, and academic self-sufficiency. When academic motivation increases, there is a moderate increase in academic self-sufficiency. These 
findings, however, denoted a relationship with no causal factors.

\section{Summary of Methodology}

The present study employed a non-experimental quantitative correlational research design using online survey methodology. The participants completed a 75-item survey that measured the mindset, type, and level of academic motivation and academic self-efficacy in relation to academic achievement. The survey consisted of self-reporting demographic information, a 7-point Likert scale for the items testing the type of mindset (Dweck, 2010; Dweck \& Leggett, 1988), types and level of academic motivation through the utilization of the AMS (Vallerand et al., 1992), and levels of academic self-efficacy using the CASES (Owens \& Froman, 1988).

A descriptive analysis was employed to describe the basic features of the study sample, including the type and level of mindset, academic motivation, and academic selfefficacy. A Spearman rank correlation was utilized to determine the strength, as well as the positive or negative direction of relationships among the variables.

Categorical regression was employed to determine the extent to which academic achievement was related to mindset, academic motivation, and levels of academic selfefficacy.

\section{Summary of Major Findings}

1. Ninety-three percent of undergraduate communication sciences and disorder students reported GPAs that were average to higher than average.

2. Undergraduate communication sciences and disorders students have very high extrinsic motivation $(M=5.90)$ and high intrinsic motivation $(M=5.22)$. 
3. Undergraduate communication sciences and disorders students have very low amotivation $(M=1.62)$.

4. Fifty-four percent of undergraduate communication sciences and disorders students have high levels of self-efficacy.

5. Undergraduate communication sciences and disorders students reported higher levels of growth mindset $(M=4.80)$ than fixed mindset $(M=3.16)$.

6. Amotivation is related to academic achievement. Negative Betas indicated that the higher the academic achievement, the lower the amotivation.

7. Academic self-efficacy was related to academic achievement. The higher the academic self-efficacy, the higher the achievement.

8. There is no significant relationship between academic achievement and fixed mindset, growth mindset, intrinsic motivation, and extrinsic motivation.

\section{Demographic Information}

A total of 215 individuals participated in the online survey; however, five were eliminated due to limited or non-completion of the items. Therefore, statistical analyses and measurements were done on 210 surveys.

Approximately $96 \%$ of participants were female, with $79 \%$ ranging in age from 18 to 21 , and $20 \%$ ranging in age from 22 to 26 . Eighty percent of the participants identified themselves as White; 8.6\% identified themselves as Hispanic; and 5.3\% identified themselves as Black/African-American. This demographic information is similar to that of the national average for all undergraduate students in the United States, with $5 \%$ being male, and $24.5 \%$ being non-White (ASHA, 2015).

Thirty-eight percent of the respondents were college seniors, $24 \%$ juniors, $22 \%$ 
sophomores, and $16 \%$ freshmen. According to the national average, approximately $25 \%$ of all undergraduate communication sciences and disorders students in the United States are college seniors, a slightly higher percentage than the national average.

Forty percent of participants attended institutions in Michigan, 36\% in Indiana, followed by $12 \%$ in Ohio and Illinois respectively. The Communication Sciences and Disorders Education Survey Data Reports (2017) indicated that Michigan has the highest percentage of undergraduate students at $43 \%$, followed by Indiana with $30 \%$, Illinois with $20 \%$, and Ohio with $6 \%$. Finally, $63 \%$ of respondents reported GPAs between 3.6 and 4.0; 29.5\% reported GPAs between 3.1 and 3.59; and 7\% reported GPAs below 3.0.

\section{Research Question 1 Discussion}

Research Question 1: What are the types of mindset, types of academic motivation, types of academic self-efficacy, and levels of academic achievement, described by students pursuing an undergraduate degree in the field of communication sciences and disorders at selected Great Lakes States universities?

A descriptive analysis of the data was conducted to include percentage, mean, standard deviation, skewness, and frequency. Sixty-three percent of participants reported a GPA ranging between 3.6 and 4.0; $30 \%$ reported a GPA between 3.1 and 3.59; and 6\% reporting a GPA between 2.6 and 3.0. Only $1 \%$ of students reported a GPA below 2.6. Ninety-three percent of those who participated in this study achieve at levels that are average to above average (Lindsay, 2015).

Respondents reported a growth mindset mean score of $4.80(S D=1.07)$ and a

fixed mindset mean score of 3.16, with a score range from 1 to 7 . Fifty-four percent identified themselves as having a high growth mindset, while only $7 \%$ identified 
themselves as having a high fixed mindset. While such a high percentage of participants identified as having a growth mindset, these findings differ from those of Dweck (2006) who posited that $40 \%$ of the population have a growth mindset, $40 \%$ have a fixed mindset, while $20 \%$ have neither growth nor fixed, lying somewhere in the center of both mindset types.

Extrinsic motivation had the highest reported mean of 5.90 with a score range of 1 to 7 and with $89 \%$ reporting high levels of extrinsic motivation. A 6.66 mean score was reported for extrinsic motivation item \#3, which stated that the purpose for going to college is "because I think that a college education will help me better prepare for the career I have chosen." This high mean score was followed by the item \#10, "Because eventually it will enable me to enter the job market in a field that I like," with a mean score of 6.48. Intrinsic motivation had a reported mean of 5.22 with a mean score range of 1 to 7 . Sixty-four percent of students identified themselves as highly intrinsically motivated. These findings align with those of Maurer et al. (2012) who found that while not significant to academic success, allied health students reported higher levels of extrinsic motivation than intrinsic. As Lepper, Corpus, and Lyengar noted (as cited in Schunk, Pintrich, and Meece, 2008) noted, "It is tempting to think of intrinsic and extrinsic motivation as two ends of a continuum such that the higher the intrinsic motivation, the lower the extrinsic motivation; however, there is no automatic relation between intrinsic and extrinsic motivation" (p. 237).

For a specific subject, skills, or activity, an individual may be both intrinsically and extrinsically motivated. In addition, such characteristics do not exist in isolation and are affected by environmental factors such as feedback, social pressures, and 
performance-based rewards. Ryan and Deci (2000) stressed that any actions or activity engaged in for the purpose of tangible rewards do eventually undermine intrinsic motivation. Because of other factors such as environment and social influence, some may adaptively internalize those that are thought to be socially valued, hence transitioning from extrinsic to intrinsic motivation.

The long-term effects of extrinsic motivation resulted in discouragement if success was not achieved at each attempt (Karageorghis \& Terry, 2011). Ryan and Deci (2017) expressed the view that "an individual's response to rewards serves as functional significance. Such rewards, if perceived as that which controls behavior, could result in undermining intrinsic motivation; however, if seen as competence affirming, could enhance intrinsic motivation (p. 130).

Amotivation was reported with a very low mean of 1.62 (mean range $=1-7)$. Ninety-six percent of the sample reported low amotivation, with $0 \%$ of the sample reporting high amotivation. Throughout the literature, low motivation is linked to academic underachievement or low academic achievement. There is limited research directly addressing amotivation irrespective of intrinsic and extrinsic motivation. These findings, along with those of intrinsic and extrinsic motivation, were consistent with reports that those with low amotivation presented with high intrinsic and/or extrinsic motivation. Therefore, with such limited motivation, there were low levels of commitment and feelings of inadequacy, which was not the reported experience of this higher than average performing group (Taftified, 2013).

The sample population reported an academic self-efficacy mean score of 5.08 with a mean range of 1 to 7 . Fifty-four percent of the population sampled identified 
themselves as having high academic self-efficacy. It would appear that undergraduate communication sciences and disorders students who have high academic self-efficacy (54\%) may also have higher than average GPAs (63\%). These findings align with the conclusions of Bandura (1994) that those with high levels of self-efficacy actually tend to demonstrate greater accomplishments. These individuals also experienced a greater sense of well-being. College students with high self-efficacy tended to be better organized, with greater strategies for success. These students are better able to visualize their path prior to executing a task (Bandura, 1994; Schunk, 1991). Self-efficacy is considered an essential component of college success (Hsieh, Sullivan, \& Guerra, 2007).

\section{Research Question 2 Discussion}

Research Question 2: To what extent are mindset, academic motivation, and academic self-efficacy related to the academic achievement (GPA) of students pursuing an undergraduate degree in the field of communication sciences and disorders at selected Great Lakes States universities?

The Spearman rank correlation coefficient was used to measure the strength and association of the variables. This was followed by CATREG analyses. The Spearman rho revealed a strong negative monotonic correlation between growth and fixed mindset showing that those individuals with high growth mindset scores also reported low fixed mindset scores. In turn, those with high fixed mindsets had low growth mindsets. This outcome supports assertions of Dweck (2006) that while $40 \%$ of the population have a growth mindset and $40 \%$ have a fixed mindset, there is $20 \%$ of the population that lies somewhere on the continuum between both growth and fixed mindsets.

The Spearman rank correlation of intrinsic motivation noted weak to very weak 
negative and positive correlations to extrinsic motivation, amotivation, and academic self-efficacy. The dependent variable GPA was found to have a very weak monotonic correlation with growth mindset, and a weak correlation with academic self-efficacy and amotivation.

The CATREG analysis reported that the independent variables growth mindset, fixed mindset, intrinsic motivation, and extrinsic motivation revealed no significant variance, indicating that there is no relationship between these variables and the academic achievement in undergraduate communication sciences and disorders students. These findings contradict those of Blackwell et al. (2007) who concluded that growth mindset impacted positive achievement over time. Further, Dweck and Leggett (1988) stressed that mindset "is the depiction of the manner in which underlying personality variables can translate into dynamic motivational processes to produce major patterns of cognition, affect, and behavior" (p. 271). The results of this study are supported by the research of Gondida et al. (2006) who concluded that mindset (implicit theories) is not the causal factor in school achievement. These authors' findings indicated that prior school achievement and perceived academic competence (academic self-efficacy) mediated mindset. Further, Schunk (1991) confirmed that academic self-efficacy, like mindset, is developed and strengthened by prior success and achievement.

The findings of this study that a negative relationship existed between motivation and academic achievement refuted those of Kusurkar et al. (2012) who found a positive relationship between motivation and academic achievement. However, Kusurkar et al. (2012) also took into account students' study habits, study styles, and levels of commitment as factors related to achievement. Such factors such as students'study 
habits and other external factors were not considered in this current study, which may also account for the differences in findings.

A final CATREG analysis that included self-efficacy and amotivation indicated that $18 \%$ of the variance of GPA could be explained by amotivation with a 69 level of importance and academic self-efficacy with a .18 level of importance. Amotivation indicated an inverse relationship, noting that the lower the amotivation score, the higher GPA.

Self-efficacy results indicated a positive relationship to GPA, denoting that higher levels of self-efficacy are related to higher levels of achievement. These current findings are supported by those of Zimmerman et al. (1992) who found that $31 \%$ of the variance of the sample's success within a specific course was explained by academic self-efficacy. Zimmerman et al. (1992) also found that prior achievement did not significantly impact the outcome in that course, contradicting the findings of Schunk (1991) and Gondida et al. (2006) who purported that some prior achievement success can contribute to levels of academic self-efficacy. The knowledge that one has achieved in the past gives greater levels of self-belief about what can be accomplished in the future.

\section{Conclusions}

This current study sought to examine the academic achievement of undergraduate communication sciences and disorders student and the factors that mediate their academic achievement. The following conclusions were made:

A large percentage of undergraduate communication sciences and disorders students have higher than average levels of academic achievement. They are highly extrinsically motivated. However, many also consider themselves to be intrinsically 
motivated, noting therefore, that while they are at times engaging in tasks for pleasure and what can be learned, over time, they could experience discouragement if they do not achieve success. Most of the respondents reported low levels of amotivation, which was the only form of motivation in this study that was shown to be related to academic achievement. As amotivation decreased, academic achievement increased. Therefore, the results of this study confirmed that undergraduate communication sciences and disorders students do not have low levels of commitment, nor do they have feelings of inadequacy (Taftified, 2013).

The findings of this study indicated that overall, undergraduate communication sciences and disorders students had higher levels of growth mindset and low levels of fixed mindset, thus reinforcing the view that learning is based on one's development, and stretching one's ability and changeability (Dweck, 2006). Only a small percentage of this population was concerned with learning based only on intelligence and working to prove what they know, rather than what they can learn (Dweck \& Leggett, 1988). The current results, however, indicated that there is no relationship between mindset and academic achievement. While growth mindset is not directly linked to academic achievement, it has been linked to overall wellbeing (Gondida et al., 2006).

This study revealed that there is a positive relationship between academic selfefficacy and academic achievement (Bandura, 1994). Therefore, as academic selfefficacy increases, academic achievement also increases. Undergraduate communication sciences and disorders students generally have high levels of academic self-efficacy leading to positive feelings about their academic skills. They may also be more proactive, better organized, utilize greater strategies for success, be self-reflecting, and 
have stronger career aspirations (Pajares \& Urdan, 2006).

\section{Implications for Practice}

Undergraduate communication sciences and disorders students were studied to determine the strength of the relationship among academic achievement, mindset, academic motivation, and academic self-efficacy.

The findings of this study confirmed that high levels of academic self-efficacy and low levels of amotivation can significantly affect the academic achievement of undergraduate communication and sciences disorders students. There should be further investigations about the implications of increasing levels of amotivation irrespective of intrinsic and/or extrinsic motivation. One may conclude that if intrinsic and extrinsic motivation levels are increased, maintained, and nurtured, there will be adverse effects to increasing levels of amotivation. While research has confirmed that intrinsic motivation is the preferred domain of motivation and that this type of motivation can foster academic achievement and well-being, traditional academic structures emphasize extrinsic motivators (Ryan \& Deci, 2017).

The traditional grading system, assessments, tests, honor rolls and dean's lists, and punishments for incomplete or misunderstood work clearly foster the development of extrinsic motivation. Accrediting organizations, states, and institutional learning outcomes add pressure to institutions and instructors to forge through material, whether or not it is understood, assimilated, or internalized by students. Ellis Ormond (2015) recommended that extrinsic reinforcers can be used when necessary, but that they should not get in the way of preserving students' sense of autonomy.

Student autonomy and a development of purpose for their educational/training 
experience can come through specific instructional practices. Baranek (1996) and Dinther, Dochy, and Segers (2011) suggested the fostering of a healthy and "safe" class climate and an opportunity for interactive reflection in order to assist students in finding their purpose. Walter et al. (2015) stated that "instructor training in the areas of emotional intelligence, academic self-efficacy and coping strategies, will contribute to their ability to further the development of these personality dimensions among students" (p. 1213).

Through effective pedagogical approaches, instructors and higher education administrators can meet the needs of an ethnically and culturally diverse student population. Positive reinforcement, engaging students in dialogue, flipping the classroom, and creating interactive classroom experiences can increase their self-efficacy (Haskel, 2016). Such innovation by educators is critical to student success. Dweck (2010) reiterated that

teachers and administrators should send messages that intelligence is fluid, and they need to hear such messages too. They need to keep growing, especially in these challenging and changing times. Thus, they, too, need permission to learn-the freedom to stretch themselves, make mistakes, and try again. Only in growth mindset cultures, where teachers and administrators are encouraged to fulfill their potential, will they be able to help their students fulfill their potential in schools that are free of bias. (p. 29)

It is important for instructors and higher education administrators who support students, to understand the power of their words. Meaningful, timely, relevant feedback can increase or reduce self-efficacy (Schunk, 1991). However, destructive, judgmental, and insensitive interactions can decrease a student's level of self-efficacy and even increase levels of amotivation.

While classroom-based interventions are beneficial, students can also be reached 
through formal methods such as a prescribed program that addresses and builds selfefficacy and academic motivation as an institution-wide initiative. Such programs will often provide students with authentic tasks that can be applied across the experiential educational domains (Dinther et al., 2011). Such endeavors will allow students to rehearse possible scenarios as well as be cognizant of feelings, issues, and responses that could occur during the college experience. These approaches are most likely appropriate for application across other academic majors.

Interactive classroom-based teaching approaches are recommended to increase students' level of success, academic self-efficacy, and academic motivation. The concept of Universal Design for Learning (Universal Design for Learning, 2017) has revolutionized education from kindergarten to higher education. Based in the fields of architecture and cognitive neuroscience, Universal Design Learning takes the what, how, and why of learning to create goals, materials, methodology, and assessment that work for many students across various learning styles. It makes education and information more accessible and appropriate (Eagleton, 2008). It also reinforces approaches that allow for multiple means of expression, such as writing, audiovisual representation, and visual arts.

Fostering student reflection through open-ended questions, error locating, technology, and peer learning opportunities, can prove to be instrumental in fostering success, thereby increasing their academic self-efficacy and academic motivation (Merlo, 2017).

\section{Recommendations for Future Research}

The outcomes of this study could lead to future research in the following ways: 
1. Further inquiry from a qualitative perspective could be beneficial in allowing for an exploratory account of the possible underlying reasons for specific responses. Qualitative inquiry allows for in-depth investigations, interviews, and clarification of related topics (Watkins, 2012). This study revealed that undergraduate communication sciences and disorders students have high levels of extrinsic motivation. Qualitative investigation of this study could offer in-depth clarification as to this population's level of extrinsic and intrinsic motivations.

2. The replication of this study is critical for the purpose of strengthening the validity of the current findings, external validity and determining the presence of possible extraneous variables (Replication Study, 2009).

3. Chemers et al. (2001) confirmed that perceived competence may be affected by prior academic achievement and may also predict future achievement. Such findings support the need for researchers in the field to consider using longitudinal research strategies in order to provide more in-depth information on the interrelationships among the variables.

4. This study surveyed the undergraduate communication sciences and disorders students in the Great Lakes States of Michigan, Indiana, Ohio, and Illinois, resulting in findings that could be judged as somewhat biased based on the geographical regions from which the population was selected. Expanding this study to a larger geographical region of the United States, as well as including additional demographic variables such as race/ethnicity, gender and college level that are more representative of the cross-section of the U.S. population may provide stronger correlations among the variables. 
APPENDIX A

IRB APPROVAL DOCUMENTS 


\title{
Andrews OUniversity
}

April 4, 2017

Heather Ferguson

Tel. (269) 471-6469

Email: hferguson@andrews.edu

\begin{abstract}
RE: APPLICATION FOR APPROVAL OF RESEARCH INVOLVING HUMAN SUBJECTS IRB Protocol \#:17-052 Application Type: Original Dept.: Leadership

Review Category: Exempt Action Taken: Approved Advisor: Elvin Gabriel

Title: Mindset, Self-Efficacy, and Academic Motivation as Correlates of Academic Achievement among Undergraduate Students in Communication Sciences and Disorders Programs.
\end{abstract}

Your IRB application for approval of research involving human subjects entitled: "Mindset, Self-Efficacy, and Academic Motivation as Correlates of Academic Achievement among Undergraduate Students in Communication Sciences and Disorders Programs" IRB protocol \# 17-052 has been evaluated and determined Exempt from IRB review under regulation 46.101 (b) (2). You may now proceed with your research.

Please note that any future changes (see IRB Handbook pages 11-12) made to the study design and/or informed consent form require prior approval from the IRB before such changes can be implemented. Incase you need to make changes please use the attached report form.

While there appears to be no more than minimum risks with your study, should an incidence occur that results in a research-related adverse reaction and/or physical injury, (see IRB Handbook pages 12) this must be reported immediately in writing to the IRB. Any research-related physical injury must also be reported immediately to the University Physician, Dr. Katherine, by calling (269) 473-2222.

We ask that you reference the protocol number in any future correspondence regarding this study for easy retrieval of information.

Best wishes in your research.

Sincerely,

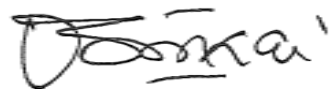

Mordekai Ongo

Research Integrity and Complaince Officer

Institutional Review Board - 4150 Administration Dr Room 322 - Berrien Springs, MI 49104-0355

Tel: (269) 471-6361 Fax: (269) 471-6543 E-mail: irb@andrews.edu 
From: IRB <irb@andrews.edu>

Subject: RE: IRB Modification 17-052 Approval

Date: May 31, 2017 at 4:39:59 PM EDT

To: Heather Ferguson <hferguson@andrews.edu>

Cc: Elvin Gabriel <gabriel@andrews.edu>

Dear Heather,

Congratulations! Your IRB modification application for approval of research involving human subjects entitled: "Mindset, Self-Efficacy, and Academic Motivation as

Correlates of Academic Achievement among Undergraduate Students in Communication Sciences and Disorders Programs" IRB protocol \# 17-052 has been evaluated and determined Exempt from IRB review under regulation 46.101 (b) (2) to include data collection at the institutions on the next page. Please find attached your letter of determination.

Thank you.

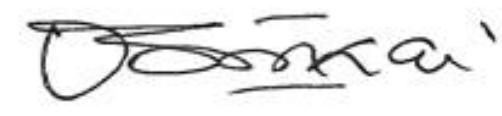

\section{Mordekai Ongo}

Research Integrity \& Compliance Officer

Andrews University

4150 Administration $\mathrm{Dr}$

Berrien Springs, MI 49104-4910

Tel. Office: 269-471-6361

Email: irb@andrews.edu

From: Heather Ferguson

Sent: Thursday, May 25, 2017 5:20 PM

To: IRB <irb@andrews.edu>

Cc: Elvin Gabriel <gabriel@andrews.edu>

Subject: IRB Modification 17-052 
APPENDIX B

SURVEY INVITATION 
From: Heather Ferguson <hferguson@andrews.edu>

Subject: RE: Permission to survey undergraduate students

Date: April 5, 2017 at 1:33:47 PM EDT

To: "Kluender, Keith R" <kkluender@purdue.edu>

Cc: "Hartwig, Maria E" <mhartwi@purdue.edu>, "Mullen, Michelle V"

$<$ mmull@purdue.edu>, "Taylor, Mary" <taylorm@purdue.edu>

\section{Greetings,}

I am a student at Andrews University completing a PhD in Higher Education Administration. My Dissertation topic is Mindset, SelfEfficacy, and Academic Motivation as Correlates of Achievement among Undergraduate Students in Communication Sciences and Disorders Programs. I am inviting you to participate in this study by completing the survey through this link below.

\section{$\underline{\text { https://www.andrews.edu/classclimate/online.php?p=Purdue }}$}

Thank you,

Heather Ferguson, MS-CCC/SLP

Speech-Language Pathologist 
APPENDIX C

INFORMED CONSENT 


\section{Andrews University \\ Informed Consent Form}

Research Topic: Mindset, Self-Efficacy, and Academic Motivation as Correlates of Academic Achievement among Undergraduate Students in Communication Sciences and Disorders Programs

Please read this consent document carefully before you decide to participate in this study.

Principal Investigator: Heather Ferguson

Advisor: Elvin Gabriel, $\mathrm{PhD}$

State about the research: This research study is a part of my research project, in partial fulfillment for my PhD in Higher Education Administration at Andrews University, Berrien Springs, MI. Your participation in this study is greatly appreciated. The purpose of this study is to determine the extent to which types of mindset, levels of self-efficacy, and types of academic motivation are correlated with academic achievement among undergraduate CSD students in various great lake states through a survey model.

Procedures: Once access to the online survey is obtained, participants would acquire detailed instructions as to how to complete the survey, which will take an average of 30 minutes to complete.

Duration of participation in study: Each participant will take approximately 30 minutes to complete the survey.

Risks and Benefits: There is no anticipated risk from participating in this research.

Voluntary Participation: Participation in this study is completely voluntary, refusal to participate will involve no penalty or loss of benefits to which you are otherwise entitled. You may discontinue participation at any time without penalty or loss of benefits to which you may otherwise be entitled.

Privacy/ Confidentiality/ Data Security: Listed are the approaches used in this survey to protect the participant's privacy and/or confidentiality.

- The researcher and the dissertation committee will have access to survey information which will be anonymous.

- All secure data will be kept on a password protected computer.

Confidentiality: This is an anonymous survey. Besides, your identity if any, will be kept confidential to the extent of the law. There will be nothing linking you to the study. None of your identifiers, if any, will be used in any report or publication. 
Whom to contact: If you have any questions about your rights as a subject/participant in this research, contact my advisor Elvin Gabriel, EdD at (269) 471-6223/

gabriel@andrews.edu ; or researcher, Heather Ferguson at (269) 471-6369/

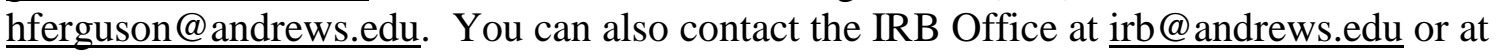
(269) 471-6361.

Statement of Consent: I have read the above information, and have received answers to any questions I asked. Click accept to advance to the survey which would imply your consent to take part in the study. Click decline to withdraw from survey participation. 
APPENDIX D

STUDY SURVEY 
Undergraduate Communication Sciences and Disorders Survey

1. Andrews University Informed Consent

Research Topic Mindset, Self-Efficacy, and Academic Motivation as Correlates of Academic Achievement among Undergraduate Students in Communication Sciences and Disorders Programs

Please read this consent document carefully before you decide to participate in this study.

Principal Investigator: Heather Ferguson

Advisor: Elvin Gabriel, PhD

State about the research: This research study is a part of my research project, in partial fulfillment for my PhD in Higher Education Administration at Andrews University, Berrien Springs, MI. Your participation in this study is greatly appreciated. The purpose of this study is to determine the extent to which types of mindset, levels of selfefficacy, and types of academic motivation are correlated with academic achievement amount undergraduate CSD students in various great lake states through a survey model.

Procedures: Once access to the online survey is obtained, participants would acquire detained instructions as to how to complete the survey, which will take an average of 30 minutes to complete.

Duration of participation in study: Each participant will take approximately 30 minutes to complete the survey.

Risks and Benefits: There is no anticipated risk from participating in this research.

Voluntary Participation: Participation in this study is completely voluntary, refusal to participate will involve no penalty or loss of benefits to which you are otherwise entitled. You may discontinue participation at any time without penalty or loss of benefits to which you may otherwise be entitled.

Privacy/ Confidentiality/ Data Security: Listed are the approaches used in this survey to protect the participant's privacy and/or confidentiality.

-The researcher and the dissertation committee will have access to survey information which will be anonymous. -All secure data will be kept on a password protected computer.

Confidentiality: This is an anonymous survey. Besides, your identity if any, will be kept confidential to the extent of the law. There will be noting linking you to the study. None of your identifiers, if any, will be used in any report or publication. Whom to contact: If you have any questions about your rights as a subject/participant in this research, contact my advisor Elvin Gabirel, EdD at (269) 471-6223/ gabriel@andrews.edu ; or researcher, Heather Ferguson at (269) 471-6369/ hferguson@andrews.edu. You can also contact the IRB Office at irb@andrews.edu or at (269) 4716361.

\begin{tabular}{|c|c|c|c|}
\hline \multicolumn{4}{|c|}{ 2. Demographics } \\
\hline \multicolumn{4}{|c|}{2.1 Gender? } \\
\hline & qMale & $\square$ Female & \\
\hline \multicolumn{4}{|c|}{2.2 Age? } \\
\hline & ㅁ 18-21 & $\square 22-26$ & $\square 26+$ \\
\hline \multirow[t]{2}{*}{2.3} & Race? & & \\
\hline & $\begin{array}{l}\text { q Asian/Pacific Islander } \\
\square \text { Native American or Indian }\end{array}$ & $\begin{array}{l}\text { 口 Black or African American } \\
\square \text { White }\end{array}$ & ם Hispanic/Latino \\
\hline 2.4 & $\begin{array}{l}\text { What is your field of interest? } \\
\text { q Speech-Language Pathology }\end{array}$ & $\square$ Audiology & q other \\
\hline 2.5 & $\begin{array}{l}\text { What is your current college level? } \\
\text { q Freshman } \\
\square \text { Senior }\end{array}$ & q Sophomore & qJunior \\
\hline \multicolumn{4}{|c|}{2.6 What is your current cumulative GPA? } \\
\hline
\end{tabular}


3.1 You have a certain amount of intelligence, and you can't really do much to change it.

3.2 Your intelligence is something about you that you can't change very much.

3.3 No matter who you are, you can significantly change your intelligence level.

3.4 To be honest, you can't really change how intelligent you are.

3.5 You can always substantially change how intelligent you are.

3.6 You can learn new things, but you can't really change your basic intelligence.

3.7 No matter how much intelligence you have, you can always

ロ ロ ロ ロ

ㅁㅁㅁㅁ change it quite a bit.

3.8 You can change even you basic intelligence level considerably. व व व व

\section{Why Do You Go To college?}

Indicate to what extent each of the following items presently corresponds with why you go to college.

4.1 Because with only a high-school degree I would not find a high-paying job later on

4.2 Because I experience pleasure and satisfaction while learning new things.

4.3 Because I think that a college education will help me better prepare for the career I have chosen.

4.4 For the intense feelings I experience when I am communicating my own ideas to others.

4.5 Honestly, I don't know: I really feel that I am wasting my time in school

4.6 For the pleasure I experience while surpassing myself in my studies.

4.7 To prove myself that I am capable of completing my college degree.

4.8 In order to obtain a more prestigious job later on.

4.9 For the pleasure I experience when I discover new things never seen before.

4.10 Because eventually it will enable me to enter the job market in a field that I like.

4.11 For the pleasure that I experience when I read interesting authors.

ロ ロ ロ ロ ロ

4.12 I once had good reasons for going to college; however, now wonder whether I should continue.

ㅁㅁㅁㅁ

ㅁㅁㅁ

ㅁㅁㅁㅁㅁ

ㅁ $\square$ ㅁ

ㅁㅁㅁㅁ

ㅁ口םロロ 
4.13 For the pleasure that I experience while I am surpassing myself in one of my personal accomplishments.

4.14 Because of the fact that when I succeed in college I feel important.

ロロロロロロロ

4.15 Because I want to have "the good life" later on.

ㅁㅁ व व

4.16 For the pleasure that I experience in broadening my

ロ ロ ロ व व knowledge about subject which appeal to me.

4.17 Because this will help me make a better choice regarding my career orientation.

4.18 For the pleasure that I experience when I feel completely absorbed by what certain authors have written.

4.19 I can't see why I go to college and frankly, I couldn't care less.

ロロロロロロ ロ

4.20 For the satisfaction I feel when I am in the process of accomplishing difficult academic activities.

4.21 To show myself that 1 am an intelligent person.

ロロロロロロ ロ

4.22 In order to have a better salary later on.

व व व व व

4.23 Because my studies allow me to continue to learn about many

व व व व व things that interest me.

4.24 Because I believe that a few additional years of education will improve my competence as a worker.

4.25 For the "high" feeling that I experience while reading about various interesting subjects.

4.26 I don't know; I can't understand what I am doing in school.

4.27 Because college allows me to experience a personal satisfaction in my quest for excellence in my studies.

What is your confidence level in doing each of the behaviors below?

5.1 Taking well organized notes during a lecture.

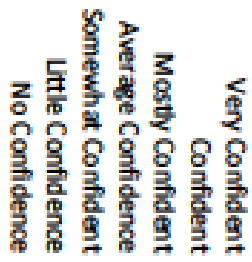

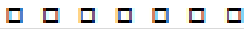

5.2 Participating in a class discussion.

ㅁㅁㅁㅁ

5.3 Answering a question in a large class.

ㅁㅁ व व

5.4 Answering a question in a small class.

ㅁㅁㅁㅁ

5.5 Taking "objective" tests (multiple-choice, T-F, matching).

ㅁㅁㅁㅁ

5.6 Taking essay tests.

ㅁㅁㅁㅁ

5.7 Writing a high quality term paper.

ㅁㅁㅁ व

5.8 Listening carefully during a lecture on a difficult topic.

व व व व व

5.9 Tutoring another student.

व व व व व

5.10 Explaining a concept to another student.

ㅁㅁ व व

5.11 Asking a professor in class to review a concept you don't understand.
ロ ロロロロ ロ 


\section{College Questionnaire [Continue]}

5.12 Earning good marks in most courses.

ㅁㅁㅁㅁ व

5.13 studying enough to understand content thoroughly.

ㅁㅁㅁㅁ

5.14 Running for student government office.

ㅁㅁㅁㅁㅁ

5.15 Participating in extra-curricular events (sports, clubs).

ㅁㅁㅁ

5.16 Making professors respect you.

ㅁㅁㅁ व

5.17 Attending class regularly.

ロ ロ व व व

5.18 Attending class consistently in a dull course.

ㅁㅁㅁㅁㅁ

5.19 Making a professor think you're paying attention in class.

ㅁㅁㅁ व

5.20 Understanding most ideas you read in your texts.

ㅁㅁㅁㅁ व

5.21 Understanding most ideas presented in class.

ㅁํ व व

5.22 Performing simple math computations.

व व व व व

5.23 Using a computer.

ㅁㅁㅁ व

5.24 Mastering most content in a math course.

ㅁㅁㅁㅁ

5.25 Talking to a professor privately to get to know him or her.

व व व व व

5.26 Relating course content to material in other courses.

ㅁㅁㅁㅁ

5.27 Challenging a professor's opinion in class.

व व व व व

5.28 Applying lecture content to a laboratory session.

ㅁㅁㅁㅁ व

5.29 Making good use of the library.

ㅁㅁㅁㅁ

5.30 Getting good grades.

व ㅁㅁㅁ

5.31 Spreading out studying instead of cramming.

ㅁㅁㅁㅁ

5.32 Understanding difficult passages in textbooks.

ㅁㅁㅁㅁ व

5.33 Mastering content in a course you're not interested in.

ロロロロロロ ロ 
APPENDIX E

SCALE USE PERMISSIONS 
11 October 2015

Dear Researcher,

Thank you for your inquiry about the College Academic Self-Efficacy Scale (CASES). You are welcome to use CASES. I've included a copy of the scale below. Here are a few summary points about the scale.

Items are scored as A ("quite a lot") $=5 \ldots \mathrm{E}$ ("very little") $=1$. On the other hand, because we read from left to right, data entry is faster letting $A=1$, and $E=5$. If you enter data with $\mathrm{A}=1$, then let the computer recode the values so that $\mathrm{A}$ becomes 5 , B becomes 4 , etc. In calculating an overall CASES score, we prefer calculating a mean rather than a sum.

You may wish to modify questionnaire instructions to best fit your application. For example, if you need informed consent, you might say something like "Filling out this questionnaire is completely voluntary and confidential. There are no penalties for not participating, and you may quit at any time."

The next page shows the CASES items. Following that is a conversation about scoring CASES, plus some normative data.

Best wishes in your research.

Sincerely,

Steven V. Owen, Professor (retired)

Department of Epidemiology \& Biostatistics

University of Texas Health Science Center at San Antonio

7703 Floyd Curl Dr., MC 7802

San Antonio, TX 78229-3900

Internet: svo@vbbn.com

OR@ steven.owen@uconn.edu 
From: Psychology Roots <scales.psychologyroots@gmail.com>

Subject: Re: Scale Request "AMS C 28"

Date: August 1, 2016 at 5:43:40 AM EDT

To: hferguson@andrews.edu

Please receive

\section{AHMED MUJTABA OWAISI INCHARGE RESEARCH SECTION,} www.psychologyroots.com

Please share your collection of scales with us for this kind deed. Thanks

On Mon, Jul 25, 2016 at 3:32 AM, Heather Ferguson $<$ wordpress@research.psychologyroots.com> wrote:

From: Heather Ferguson <hferguson@andrews.edu>

Subject: AMS C 28

Message Body:

Name: Heather Ferguson

Email: hferguson@andrews.edu

Research Topic: correlation between ethnicity, college student motivation and entity/incremental theories..

Qualification: PhD

Supervisor: Jay Brand

Supervisor Email: Brand@ andrews.edu

Scale Required: AMS C 28

Institute Name: Andrews University

Campus: Main Campus

City: Berrien Springs

Institute Website:http://www.andrews.edu

This e-mail was sent from a contact form on Research Directory I An initiative of Psychology Roots (http://www.psychologyroots.com) 
From: Carol Dweck <dweck@stanford.edu>

Subject: Re: Permission to Use Mindset Test Questions

Date: July 25, 2016 at 9:40:12 AM EDT

To: Heather Ferguson <hferguson@andrews.edu>

Hi Heather,

Of course you have my permission--but please use the attached scale.

I wish you the best with your research.

Sincerely,

Carol Dweck

Lewis \& Virginia Eaton Professor of Psychology

Department of Psychology

Stanford University

Stanford, CA 94035

From: Heather Ferguson <hferguson@andrews.edu>

Sent: Sunday, July 24, 2016 4:00 PM

To: Carol Dweck

Subject: Permission to Use Mindset Test Questions

Good evening Dr. Dweck,

My name is Heather Ferguson and I am a PhD student at Andrews University. The focus of my study is looking at the correlation/ relationship between ethnicity, college student motivation and mindset of sophomore and junior speech-language pathology students. I would like permission to use the mindset test questions found on your Mindset website. Thank you in advance 


\section{REFERENCE LIST}




\section{REFERENCE LIST}

Academic achievement. (2017). Retrieved from https://www.reference.com/education/ definition-academic-achievement-d765166a90871 dcd

Ali, S., Haider, A., Munir, F., Khan, H., \& Ahmed, A. (2013). Factors contributing to the students' academic performance: A case study of Islamia university subcampus. American Journal of Educational Research, 1(8), 283-289.

American Speech-Language and Hearing Association (ASHA). (2017). Retrieved from http://www.asha.org/

American Speech-Language Hearing Association Academic Affairs Board. (2015). The role of undergraduate education in communication sciences and disorders. Rockville, MD: ASHA.

Amrai, K., Motlagh, S., Zalani, H., \& Parhon, H. (2011). The relationship between academic motivation and academic achievement students. Procedia Social and Behavioral Sciences, 15, 399-402. doi: 10.1016/ j.sbspro.2011.03.111

Avci, O., Ring, E., \& Mitchell, L. (2015). Stakeholders in U.S. higher education: An analysis through two theories of stakeholders. The Journal of Knowledge Economy \& Knowledge Management, 10, 45-54.

Balduf, M. (2009). Underachievement among college students. Journal of Advanced Academics, 20(2), 274-294.

Bandura, A. (1994). Self-efficacy. In V. S. Ramachaudran (Ed.), Encyclopedia of human behavior (Vol. 4, pp. 71-81). New York, NY: Academic Press. (Reprinted in H. Friedman [Ed.], Encyclopedia of mental health. San Diego, CA: Academic Press, 1998).

Bandura, A. (1977). Self-efficacy: Toward a unifying theory of behavioral change. Psychological Review, 84(2), 191-215.

Bandura, A. (1997). Self-efficacy: The exercise of control. New York, NY: Freeman.

Baranek, L. (1996). The effect of rewards and motivation on student achievement. Retrieved from http://scholarworks.gvsu.edu/cgi/viewcontent. cgi? article $=1292 \&$ context $=$ theses 
Blackwell, L., Trzesniewski, K., \& Dweck, C. (2007). Implicit theories of intelligence predict achievement across an adolescent transition: A longitudinal study and an intervention. Child Development, 78(1), 246-263.

Briceno, E. (2012, November 18). The power of belief-mindset and success [Video file]. Retrieved from https://www.youtube.com/watch? $\mathrm{v}=\mathrm{pN} 34 \mathrm{FNbOKXc} \& \mathrm{t}=304 \mathrm{~s}$

Bureau of Labor and Statistics. (2015). Speech-language pathologist. Retrieved from https://www.bls.gov/ooh/healthcare/speech-language-pathologists.htm

Categorical Regression (CATREG). (2012). Retrieved from https://www.ibm.com/ support /knowledgecenter/SSLVMB_21.0.0/com.ibm.spss.statistics.help/ idh_catr.htm

Chemers, M., Hu, L., \& Garcia, B. (2001). Academic self-efficacy and first-year college student performance and adjustment. Journal of Educational Psychology, 93(1), 55-64.

Cherry, K. (2016). What is reciprocal determinism? Retrieved from https://www.verywell .com/what-is-reciprocal-determinism-2795907

Clark, M., \& Schroth, C. (2010). Examining relationships between academic motivation and personality among college students. Learning and Individual Differences, 20, 19-24. Retrieved from http://ac.els-cdn.com

Claro, S., Paunesku, D., \& Dweck, C. (2016). Growth mindset tempers the effects of poverty on academic achievement. Retrieved from https://web.stanford .edu/ paunesku/articles /claro_2016.pdf

Cokley, K. (2003). What do we know about the motivation of African American students? Harvard Educational Review, 73(4), 524-558.

Communication Sciences and Disorders Education Survey Data Reports. (2017). Retrieved from http://www.asha.org/Academic/HES/CSD-Education-SurveyData-Reports/

Communication Sciences and Disorders Education Trend Data Undergraduate Programs 2010-2011 to 2014-2015. (n.d.). Retrieved from http://www.asha.org/ uploadedFiles/Trend-Report-AYs-2010-2011-through-2014-2015.pdf

Conti, R. (2000). College goals: Do self-determined and carefully considered goals predict intrinsic motivation, academic performance, and adjustment during the first semester? Social Psychology of Education, 4, 189-211. Retrieved from http://download .springer.com 
Cronbach's alpha: Simple definition, use and interpretation. (2017). Retrieved from http://www.statisticshowto.com/cronbachs-alpha-spss/

Cukor, G. (Director). (1964). My Fair Lady [Motion picture], USA: Warner Bros. Retrieved from http://www.imdb.com/title/tt0058385/

DeCastella, K., \& Byrne, D. (2015). My intelligence may be more malleable than yours: The revised implicit theories of intelligence (self-theory) scale is a better predictor of achievement, motivation and student disengagement. Retrieved from https://openresearch-repository.anu.edu.au/bitstream/1885/13127/2/De\% 20Castella\%20and\%20Byrne\%20My\%20Intelligence\%20May\%20Be\%20More\% 20Malleable\%202015.pdf

Deci, E. (1975). Intrinsic motivation. New York, NY: Plenum Press.

Deci, E. (1995). Why we do what we do: Understanding self-motivation. New York, NY: Penguin.

Deci, E. (2012, August 13). Promoting motivation, health, and excellence [Video file]. Retrieved from https://www.youtube.com/watch?v =VGrcets0E6I\&amp; $t=645 \mathrm{~s}$

Deci, E. \& Ryan, R. (1985). Intrinsic motivation and self-determination in human behavior. New York, NY: Plenum Press.

Deci, E., \& Ryan, R. (2002). Improving academic achievement: Impact of psychological factors on education. J. Aronson (Ed.). San Diego, CA: Elsevier.

Dinther, M., Dochy, F., \& Segers, M. (2011). Factors affecting students' self-efficacy in higher education. Educational Research Review, 6(2), 95-108.

Diseth, A., Meland, E., \& Breidablik, H. J. (2014). Self-beliefs among students: Grade level and gender differences in self-esteem, self-efficacy and implicit theories of intelligence. Learning \& Individual Differences, 35, 1-8.

Durm, M. W. (1993). An a is not an a: A history of grading. The Educational Forum, 57, $1-4$.

Durso S., Da Cunha, J., Neves, P., \& Texeira, J. (2016). Motivational factors for the master's degree: A comparison between students in accounting and economics in the light of the self-determination theory. USP, São Paulo, 27(71), 243-258.

Dweck, C. (2000). Self-theories: Their role in motivation, personality and development. Philadelphia, PA: Taylor \& Francis.

Dweck, C. (2006). Mindset: The new psychology of success. New York, NY: Random House. 
Dweck, C. (2010). Mind-sets and equitable education. Principal Leadership. Retrieved from file:///C:/Users/hferguson/Downloads/Mind-sets-and-EquitableEducation.pdf

Dweck, C. (2014, October 9). Developing a growth mindset [Video file]. Retrieved from https://www.youtube.com/watch?v=hiiEeMN7vbQ

Dweck, C. (2015). Carol Dweck revisits the "growth mindset." Retrieved from http://www.edweek.org/ew/articles/2015/09/23/carol-dweck-revisits-the-growthmindset.html

Dweck, C., Chiu, C., \& Hong, Y. (1995). Implicit theories and their role in judgments and reactions: A world from two perspectives. Psychological Inquiry, 6(4), 267285.

Dweck. C., \& Leggett, E. (1988). A social-cognitive approach to motivation and personality. Psychological Review, 95(2), 256-273.

Dweck, C., \& Molden, D. (2005). Self-theories: Their impact on competence motivation and acquisition. In A. J. Elliot \& C. S. Dweck (Ed.), Handbook of competence and motivation (pp. 122-140). New York, NY: Guilford Press.

Eagleton, M. (2008). Universal design for learning. Retrieved from https://www .ebscohost.com/uploads/imported/thisTopic-dbTopic-1073.pdf

Eccles, J., \& Wigfield, A. (2002). Motivational beliefs, values, and goals. Annual Review of Psychology, 53, 109-132.

Edfind. (2014). Retrieved from http://www.asha.org/edfind/

Elliot, A., \& Dweck, C. (2005). Handbook of competence and motivation (Ed.). New York, NY: Guilford Press.

Elliot, A., \& Harackiewicz, J. (1994). Goal setting, achievement orientation, and intrinsic motivation: A mediational analysis. Journal of Personality and Social Psychology, 66(5), 968-980.

Elliot, A., Maier, M., Binser, M., Friedman, R., \& Pekrun, R. (2009). The effect of red on avoidance behavior in achievement contexts. Personality and Social Psychology Bulletin, 35, 365-375.

Erdem, C., Senturk, I., \& Arslan, C. K. (2007). Factors affecting grade point average of university students. The Empirical Economics Letters, 6(5), 359-368.

Explorable.com (2009, Jun 12). Replication study. Retrieved October 06, 2017, from Explorable.com: https://explorable.com/replication-study. 
Fairchild, A., Horst, J., Finney, S., \& Barron, K. (2005). Evaluating existing and new validity evidence for the academic motivation scale. Contemporary Educational Psychology, 30, 331-358. Retrieved from http://ac.els-cdn.com

Federal Student Aid. (n.d.). Retrieved from https://studentaid.ed.gov/sa/about

Gallagher, S. (n.d.). Causes and consequences of underachievement and nonachievement. Retrieved from https://www.rfwp.com/samples/whats-wrong-withyou.pdf

Gehrz, C. (2012, March 6). Grading [Web log post]. Retrieved from https://pietistschoolman.com/2012/03/06/grading/

Geiger, R. (2011). The ten generations of American higher education. In P. Altbach, P. Gumport, \& R. Berdahl (Eds.), American higher education in the twenty-first century: Social, political, and economic challenges (3rd ed., pp. 37-68). Baltimore, MD: Johns Hopkins University Press.

Goldrick-Rab, S., \& Cook, M. (2011). College students in changing contexts. In P. Altbach, P. Gumport, \& B. Berdahl (Eds.), American higher education in the 21st century: Social, political, and economic challenges (3rd ed., pp. 254-78). Baltimore, MD: Johns Hopkins University Press.

Gondida, E., Kiosseoglou, G., \& Leondari, A. (2006). Implicit theories of intelligence, perceived academic competence and school achievement: Testing alternative models. The American Journal of Psychology, 119(2), 223-238. Retrieved from http://www.jstor.org

Gottfried A. (1985). Academic intrinsic motivation in elementary and junior high school students. Journal of Educational Psychology, 77(6), 631-645.

Harter, S. (1981). A new self-report scale of intrinsic versus extrinsic orientation in the classroom: Motivational and informational components. Developmental Psychology, 17(3), 300-312.

Hartmann, T. (2012, September 25). A short history of grading [Web log post]. Retrieved from http://joe-bower.blogspot.com/2012/09/a-short-history-of-grading.html

Haskell, N. (2016). Classroom strategies to improve student self-efficacy and learning outcomes. Retrieved from http://www.pearsoned.com/education-blog/improveself-efficacy-learning-outcomes/

Hegarty, N. (2010). Application of the academic motivation scale to graduate school students. The Journal of Human Resource and Adult Learning, 6(2), 48-55. Retrieved from http://www.hraljournal.com 
Heider, F. (1958). The psychology of interpersonal relations. New York, NY: Wiley.

Hooper, T. (2010). The king's speech [Motion picture]. United Kingdom: See-Saw Films. Retrieved from http://www.kingsspeech.com/

Hsieh, P., Sullivan, J., \& Guerra, N. (2007). A closer look at college students: Selfefficacy and goal achievement. Journal of Advanced Academics, 18(3), $454-$ 476.

Isiksal, M. (2010). A comparative study on undergraduate students' academic motivation and academic self-concept. The Spanish Journal of Psychology, 13(2), 572-585.

Retrieved from http://www.redalyc.org

Johnson, K. (2000, May 26). The peer effect on academic achievement among public elementary school students [Web log post]. Retrieved from http://www.heritage .org/education/report/the-peer-effect-academic-achievement-among-publicelementary-school-students.

Jones, B. D. (2014, January 6). Self-determination theory $v 1$ [Video file]. Retrieved from https://www.youtube.com/watch?v=v84XxJkqvbU\&amp;t=110s

Kanter, M., Ochoa, E., Nassif, R., \& Chong, F. (2011). Meeting President Obama's 2020 college completion plan [PowerPoint slides]. Retrieved from https://www.ed.gov /sites/default/files/winning-the-future.ppt

Karageorghis, C., \& Terry, P. (2011). Inside sports psychology. Champaign, IL: Human Kinetics.

Kelly, G. A. (1955). The psychology of personal constructs. New York, NY: Norton.

Kusurkar, R., Cate, T., Vos, C., Westers, P., \& Croiset, G. (2012). How motivation affects academic performance: A structural equation modelling analysis. Advances in Health Science Education, 1-13.

Lackey, C. (2013). Relationships between motivation, self-efficacy, mindsets, attributions, and learning strategies: An exploratory study. Retrieved from http://ir.library.illinoisstate.edu/cgi/viewcontent.cgi?article=1076\&context=etd

Leal, E., Miranda, G., \& Souza, C. (2012). Self-determination theory: An analysis of student motivation in an accounting degree program. Retrieved from http://www.scielo.br/pdf/rcf/v24n62/en_07.pdf

Lennon, J. M. (2010). Self-efficacy. In J. A. Rosen, E. J. Glennie, B. W. Dalton, J. M. Lennon, \& R. N. Bozick (Eds.), Noncognitive skills in the classroom: New perspectives on Educational Research (pp. 91-116). Research Triangle Park, NC: RTI Press. 
Leondari, A., \& Gialamas, V. (2002). Implicit theories, goal orientations, and perceived competence: Impact on students' achievement behavior. Psychology in the Schools, 39(3), 279-291. http://www.uky.edu

Lindsay, S. (2015, August 7). What's the average college GPA? By major? [Web log post]. Retrieved from http://blog.prepscholar.com/average-college-gpa-by-major

Long, J. F., Monoi, S., Harper, B., Knoblauch, D., \& Murphy, P. K. (2007). Academic motivation and achievement among urban adolescents. Urban Education, 42, 196222.

Magno, C. (2012). Implicit theories of intelligence, achievement goal orientation, and academic achievement of engineering students. The International Journal of Research and Review, 9, 32-43.

Mansharamani, V. (2016). How an epidemic of grade inflation made A's average. Retrieved from http://www.pbs.org/newshour/making-sense/column-how-anepidemic-of-grade-inflation-made-as-average/

Maurer, T., Allen, D., Gatch, D., Shankar, P., \& Sturges, D. (2012). Students' academic motivation in allied health classes. The Internet Journal of Allied Health Sciences and Practices, 10(1), 1-12. Retrieved from http://nsuworks.nova.edu

McGrew, K. (2011). Beyond IQ series \# 5: Motivational orientation--Do I want to do this activity and why? Retrieved from http://www.iqscorner.com/search? $\mathrm{q}=$ related+to +this+question+include $\% 2 \mathrm{C}+$ but+are+not+limited+to $\% 2 \mathrm{C}+$ achievement+interest $\mathrm{s}+$ and+values $\% 2 \mathrm{C}+$ intrinsic+motivation $\% 2 \mathrm{C}+$ academic+goal+orientation $\% 2 \mathrm{C}+\mathrm{a}$ nd+social+goals+and+their+relations+to+motivation

McLeod, S. (2008). Correlation. Retrieved from https://www.simplypsychology.org /correlation.html

Mehrabi, T., Behzadi, S., Sabouri, F., \& Alavi, M. (2016). Assessment of the effect of the CBT on motivation of the nursing students. Iranian Journal of Nursing and Midwifery Research, 21(2), 118-123. Retrieved from http://www.ijnmrjournal.net

Merlo, C. (2017). Four interactive classroom activities for college students. Retrieved from https://tophat.com/blog/interactive-classroom-activities/

Mindset works. (2017). Retrieved from https://www.mindsetworks.com/page/increasestudents-motivation-grades-and-achievement-test-scores

Moinester, M., \& Gottfried, R. (2014). Sample size estimation for correlations with prespecified confidence interval. Quantitative Methods Psychology, 10, 124-130. 
Motlagh, S. E., Amrai, K., Yazdani, M., Abderahim, H., \& Souri, H. (2011). The relationship between self-efficacy and academic achievement in high school students. Procedia Social and Behavioral Sciences, 15(2011), 765-768.

Murphy, L., \& Thomas, L. (2008). Dangers of a fixed mindset: Implications of selftheories research for computer science education. ITiCSE, 271-275.

My majors. (n.d.). Retrieved from https://www.mymajors.com/colleges/communicationsciences-and-disorders-major/

Neumeister, K., \& Hebert, T. (2003). Underachievement versus selective achievement: Delving deeper and discovering the difference. Journal for the Educatio of the Gifted, 26(3), 221-238. Retrieved from http://journals.sagepub.com

Omrod, J. E. (2015). Essentials of educational psychology: Big ideas to guide effective teaching $\left(4^{\text {th }}\right.$ ed.). Upper Saddle River, NJ: Pearson Education Inc.

Owens, S. \& Froman, R. (1988). Development of a college academic self-efficacy scale. Retrieved from http://files.eric.ed.gov/fulltext/ED298158.pdf

Ozer, E., \& Akgun, O. (2015). The effects of irrational beliefs on academic motivation and academic self-efficacy of candidate teachers of computer and instructional technologies education department. Social and Behavioral Sciences, 197, 12871292.

Pajares, F., \& Urdan, T. (Eds.). (2005). Self-efficacy and adolescence. Greenwich, CT: Information Age.

Pakdel, B. (2013). The historical context of motivation and analysis theories individual motivation. International Journal of Humanities and Social Science, 3(18), 240247.

Perform well. (n.d.). Retrieved from http://www.performwell.org/

Phillips, T. (2011). Brazil census shows African-Brazilians in the majority for the first time. Retrieved from https://www.theguardian.com/world/2011/nov/17/brazil census-african-brazilians-majority

Planchard, M., Daniel, K., Maroo, J., Mishra, C. \& McLean, T. (2015). Homework, motivation, and academic achievement in a college genetics course. Bioscene, 4l(2), 11-18. Retrieved from http://files.eric.ed.gov

Qadeer, M. (2009). Motivation in the history [PowerPoint slides]. Retrieved from https://www.slideshare.net/Subjectmaterial/chap-2-motivation-in-the-history 
Research methodology. (2016). Retrieved from http://research-methodology.net/researchmethods/survey-method/

Robbins, S., Lauver, K., Le, H., Davis, H., Langley, R., \& Carlstrom, A. (2004). Do psychosocial and study skill factors predict college outcomes? A meta-analysis. Psychological Bulletin, 130(2), 261-288.

Robins, R., \& Pals, J. (2002). Implicit self-theories in the academic domain: Implications for goal orientation, attributions, affect, and self-esteem change. Self and Identity, 1, 313-336. Retrieved from http://disjointedthinking.jeffhughes.ca

Ryan, R., \& Deci, E. (2000). Self-determination theory and the facilitation of intrinsic motivation, social development, and well-being. American Psychologist, 55(1), 68-78.

Ryan, R., \& Deci, E. (2017). Self-determination theory. Basic psychological needs in motivation, development, and wellness. New York, NY: Guilford.

Scheier, M., \& Carver, C. (1985). Optimism, coping, and health: Assessment and implications of generalized outcome expectancies. Health Psychology, 4, 219247.

Schunk, D. (1991). Self-efficacy and academic motivation. Educational Psychologist, 26, 207-231.

Schunk, D., Pintrich, P., \& Meece, J. (2008). Motivation in education: Theory, research, and application. Retrieved from https://www.education.com/pdf/characteristicsintrinsic-extrinsic/

Scudder, R., Aarts, N., Golper, L. A., \& Groher, M. (2009). CAPCSD pre-conference summit on undergraduate education. Retrieved from http://www.capcsd.org/ proceedings/2009/talks/Pre-Conference $\% 20$ Summit $\% 20$ on $\% 20$ Undergraduate $\%$ 20Education $\% 20-\% 20$ Models $\% 20$ of $\% 20$ Undergraduate $\% 20$ Education $\% 20$ $\% 20 \mathrm{R} \% 20$ Scudder, $\% 20 \mathrm{~N} \% 20 \mathrm{Aarts}, \% 20 \mathrm{~L} \% 20 \mathrm{Golper} \% 20$ and $\% 20 \mathrm{M} \% 20 \mathrm{Groher}$. pdf

Self-concept. (n.d.). Dictionary.com. Retrieved from http://www.dictionary.com/ browse/self-concept

Self-esteem. (n.d.). In Merriam Webster Online. Retrieved from https://www.merriamwebster.com/dictionary/self-esteem

Spearman's correlation. (n.d.). Retrieved from http://www.statstutor.ac.uk/resources/ uploaded/spearmans.pdf 
Spearman's rank-order correlation using SPSS statistics. (n.d.). Retrieved from https://statistics.laerd.com/spss-tutorials/spearmans-rank-order-correlation-usingspss-statistics.php

Steinmayr, R., Meibner, A., Weidinger A., \& Wirthwein, L. (2014). Academic achievement. Retrieved from http://www.oxfordbibliographies.com/view/ document/obo-9780199756810/obo-9780199756810-0108.xml

Strang, T. (2015). It's more than just "flipping the class." Retrieved from https://blog.cengage.com/its-more-than-just-flipping-the-class/

Strive together. (2013, August). Beyond content: Incorporating social and emotional learning into the strivetogether framework. Volume 3: A compendium of social and emotional competency measures. Retrieved from https://www.strivetogether .org/wp-content/uploads/2017/06/StriveTogether_Beyond-Content_Social-andEmotional-Learning_v3_6.13.17.pdf

Taftified. (2013, April 13). Defining the three main types of motivation and evaluating the consequences of each type on participation in sports and physical activity [Blog post]. Retrieved from http://www.easybib.com/guides/citation-guides/apaformat/how-to-cite-a-blog-apa/

Tang, N., \& Westwood, P. (2007). Worry, general self-efficacy and school achievement: An exploratory study with Chinese adolescents. Australian Journal of Guidance \& Counselling, 17(1), 68-80.

Trochim, W. (2006). Research methods knowledge base: Survey research. Retrieved from https://www.socialresearchmethods.net/kb/survey.php

Universal design for learning. (2017). Retrieved from http://www.cast.org/ourwork/about-udl.html\#.WWweBNPyufU

Vallerand, R., Pelletier, L., Blais, M., Briere, N., Senecal, C., \& Vallieres, E. (1992). The academic motivation scale: A measure of intrinsic, extrinsic, and amotivation in education. Educational and Psychological Measurement, 52, 1003-1017.

Voegeli, S. (2008). Academic underachievement: Understanding and implications for educators. Retrieved from http://www2.uwstout.edu/content/lib/thesis/2008 /2008voegelis.pdf

Walberg, H. J. (1984). Improving the productivity of America's schools: Syntheses of thousands of researcher studies show the power of nine factors influencing learning. Educational Leadership, 19-29. 
Walberg, H. J. (2003). Improving educational productivity. Retrieved from http://intranet.niacc.edu/prescopy(1)/ILC/Improving\%20Educational\%20Producti vity.pdf

Walter, O., Shenaar-Golan, V., \& Greenberg, Z. (2015). Effect of short-term intervention program on academic self-efficacy in higher education. Psychology, 6, 11991215.

Ward, A., Stoker, H. W., \& Murray-Ward, M. (1996). Achievement and ability testsdefinition of the domain. Educational Measurement, 2, 2-5.

Watkins, D. (2012). Qualitative research: The importance of conducting research that doesn't "count." Health Promotion Practice, 13(2), 153-158.

Which states border the Great Lakes? (2017). Retrieved from https://www.reference.com/ geography/states-border-great-lakes-2202fcd47d3b5001

Why a low gpa is a problem, why it might be low, and how to raise it. (n.d.). Retrieved from http://advising.lsua.edu/docs/default-source/default-document-library/whya-low-gpa-is-a-problem.pdf?sfvrsn $=0$

Wyse, S. (2012, August 15). 4 main benefits of Survey Research [Web log post]. Retrieved from https://www.snapsurveys.com/blog/4-main-benefits-surveyresearch/

Zimmerman, B., Bandura, A., \& Martinez-Pons, M. (1992). Self-motivation for academic attainment: The role of self-efficacy beliefs and personal goal setting. American Educational Research Journal, 29(3), 663-676. 
VITA 
Name: Heather Loraine Ferguson

Date of Birth: December 26, 1969

\section{Education}

1995

MS in Speech-Language Pathology, Southern Connecticut State University, New Haven, CT

1992 BS in Communication Sciences and Disorders, Andrews University, Berrien Springs, MI

\section{Professional Experience}

2013-Present Chairperson-Department of Speech-Language Pathology and Audiology, Andrews University, MI

2014-Present Program Director, MS Program in Speech-Language Pathology Andrews University, Berrien Springs, MI

2011-Present Associate Professor, Department of Speech-Language Pathology, Andrews University, MI

2012-Present Speech-Language Pathology Consultant, Benton Harbor Charter School, Benton Harbor, MI

2000-2011 Speech-Language Pathologist, Bridgeport Public Schools, Bridgeport, CT

1998-2000 Assistant Regional Manager/Speech-Language Pathologist, Core Rehabilitation Management, Cheshire, CT

1996-1997 Speech-Language Pathologist/Dysphagia Clinical Specialist, Complex Care - Avon, CT

\section{Professional Licensures and Certifications}

1996-Present Certificate of Clinical Competence, American Speech-Language Pathology and Audiology

2013-Present Michigan Speech-Language Pathology License

2012-Present Michigan Speech Language Hearing Association

1996-2012 Connecticut Department of Health and Addiction Services License to Practice Speech-Language Pathology

2000-2011 Connecticut Department of Education

\section{Professional Organizations}

1996-Present American Speech-Language and Hearing Association

2011-Present Council on Academic Program in Communication Sciences and Disorders 